UNIVERSIDADE DE SÃO PAULO

FACULDADE DE CIÊNCIAS FARMACÊUTICAS DE RIBEIRÃO PRETO

\title{
Pesquisa e desenvolvimento de produtos cosméticos para o público masculino com óleos essenciais: caracterização da pele, eficácia clínica, perfil de consumo e influência da publicidade
}

Tese de Doutorado Direto apresentada ao
Programa de Pós-Graduação em Ciências
Farmacêuticas da Faculdade de Ciências
Farmacêuticas de Ribeirão Preto/USP para
obtenção do Título de Doutor em Ciências

Área de Concentração: Medicamentos e Cosméticos

Orientador(a): Prof ${ }^{a}$. Dra . Patrícia M.B.G. Maia Campos

Versão corrigida da Tese de Doutorado apresentada ao Programa de Pós-Graduação em Ciências Farmacêuticas. Em 29/04./20201. A versão original encontra-se disponível na Faculdade de Ciências Farmacêuticas de Ribeirão Preto/USP. 


\section{RESUMO}

INFANTE, V.H.P. Pesquisa e desenvolvimento de produtos cosméticos para o público masculino com óleos essenciais: caracterização da pele, eficácia clínica, perfil de consumo e influência da publicidade. 2021. 231 f. Tese (Doutorado). Faculdade de Ciências Farmacêuticas de Ribeirão Preto - Universidade de São Paulo, Ribeirão Preto, 2021.

O presente estudo apresenta-se de forma interdisciplina, dividido por capítulos, com os objetivos: a) conhecer o mercado consumidor masculino e os seus hábitos de vida, estudar a influência do marketing na aceitação de produtos eficazes; b) estudar a composição e segurança de óleos essenciais e nanoemulsão; c) desenvolver e avaliar a estabilidade de formulações cosméticas contendo óleos essenciais e fotoprotetores; d) caracterizar a pele masculina oleosa com tendência à acne e fotoenvelhecida, além de avaliar a eficácia clínica das formulações com óleos essenciais. Métodos: Para o estudo do comportamento do consumidor foi desenvolvido e validado um questionário sendo aplicado de forma on-line. Essa etapa foi guia para o desenvolvimento de cosméticos, sobre a representação do homem na mídia e na escolha dos óleos essenciais. O perfil de segurança e composição dos óleos essenciais de melaleuca, lavanda, tangerina e eucalipto, além de nanoemulsão de melaleuca foram avaliados por meio de métodos in vitro e ex vivo. Uma vez avaliadas as substâncias ativas a serem utilizadas, partimos para a etapa de desenvolvimento de formulações cosméticas, onde desenvolvemos uma base cosmética com amidos de milho e tapioca. Essa base foi aplicada no desenvolvimento de formulações fotoprotetoras e de cosméticos com óleos essenciais. Todas as formulações tiveram seu perfil de textura e reologia avaliados, bem como estabilidade em longo prazo. As formulações fotoprotetoras foram estudadas para entender como a textura e reologia estão relacionadas com o FPS e proteção na luz visível. A partir de todos esses conhecimentos, avaliamos a pele masculina jovem (entre 18 e 28 anos), oleosa com tendência à formação de comedões e fotoenvelhecida. Os participantes foram recrutados para entrevistas presenciais e caracterização da pele por meio de técnicas de biofísica e imagem da pele. Todos foram questionados quanto ao uso de cosméticos. Na etapa referente à pesquisa clínica de eficácia dos óleos essenciais, 66 participantes do sexo masculino foram recrutados e divididos em 5 grupos em um estudo randomizado, duplo-cego, placebo-controle. Como resultado, encontramos um distanciamento entre o homem brasileiro e os produtos cosméticos de cuidados com a pele, com certa resistência ao uso de protetor solar com frequência. Dessa forma, nos estudos de caracterização observamos um processo de fotoenvelhecimento precoce e de pele oleosa com alta densidade de comedões. Os óleos essenciais apresentaram boa segurança, apenas o de tangerina apresentou uma alta penetração através do estrato córneo e citotoxicidade dependente de sua concentração. Dessa forma, o estudo clínico foi proposto com proporções iguais dos óleos essenciais, a fim de reduzir a proporção desse óleo e contornar os problemas de segurança encontrados. Os protetores desenvolvidos apresentaram interessante relação entre as características físico-mecânicas e uma melhor performance no FPS e proteção da luz visível. A combinação de uso de fotoprotetor e formulação noturna com óleos essenciais apresentou resultados clínicos satisfatórios. A combinação dos quatro óleos em igual proporção apresentou melhora da barreira da pele e os grupos de melaleuca e nanoemulsão de melaleuca melhoraram as características morfológicas e estruturais da pele masculina jovem. $\mathrm{O}$ uso de cosméticos impactou positivamente os homens, mostrando que esse é um público aberto ao setor cosmético, mas que ainda encontra algumas barreiras associadas ao seu uso.

Palavras-chave: cosméticos; óleos essenciais; pele masculina; fotoenvelhcimento; fotoproteção; microscopia confocal de reflectância a laser 
1. INTRODUÇÃO 
O estudo do comportamento do consumidor é uma área essencial para o marketing, sendo um dos assuntos mais relevantes para qualquer empresa que queira ser bem-sucedida. No entanto, não basta analisar o comportamento isoladamente, é preciso entender por que as pessoas agem de determinada maneira. Consumidores de produtos distintos possuem características diferenciadas, neste quesito, torna-se indispensável que cada segmento de mercado entenda quais os desejos e necessidades dos consumidores frente ao seu produto (ANGONESE, 2008).

Atualmente, os cosméticos apresentam-se em destaque no comércio, não só no Brasil, mas mundialmente. Por estar em evidência, tanto na mídia quanto nos lares dos consumidores, esse tipo de produto tornou-se motivo de pesquisas acadêmicas e de mercado em diversos campos de estudo, principalmente no marketing (INFANTE, MELO \& MAIA CAMPOS, 2018).

Consumir está estritamente relacionado com o ambiente em que o consumidor se encontra, além da inegável influência das mudanças vividas em sociedade. Mais do que simplesmente usufruir, os consumidores têm buscado expressar e redefinir sua individualidade perante seu meio social. Esse tipo de comportamento tem sido observado notoriamente entre as mulheres que, desde sempre, desafiam os estereótipos convencionais das representações (CARVALHO, 2010).

Os últimos anos têm sido marcados por uma recolocação da mulher no mercado de trabalho, além do crescimento de movimentos feministas que lutam por direitos de igualdade entre os gêneros (SOUZA, 2015). O movimento feminista caracteriza-se, entre vários outros aspectos, por redefinir a classificação de gênero dentro da sociedade. Vale ressaltar que gênero é uma construção social, além do biológico. Há uma tendência em absorver a ideia da construção de gênero como um aspecto social que precisa ser repensado e incorporado ao estudo da relação do consumidor com cosméticos (DE MORAES KYRILLOS, ALMEIDA, 2015).

Isso porque para o mercado cosmético não é diferente, tanto modelos masculinos como femininos estão sendo reconstruídos, por meio das simbologias de gestos, atitudes e o modo de lidar com a sexualidade e o próprio corpo. Houve uma mudança no padrão de comportamento ligado aos gêneros. Diante das conquistas femininas, o homem acabou perdendo a função máxima de provedor da família herdada da sociedade patriarcal e iniciou um processo de transformação da persona social e da intimidade tornando-se mais participativo dentro de casa e apto a dividir cada vez mais as responsabilidades com a mulher (FURTADO, 2007). 
Cada vez mais afetado pelas mudanças sociais, o homem tem sentido a necessidade de expressar sua individualidade de forma mais variada, independentemente de sua orientação sexual. Entretanto, polarizar esse tipo de mercado pode colaborar ainda mais com as diferenças observadas entre os gêneros, pois pode existir uma predominância de discurso machista dentro da publicidade veiculada, reafirmando a ideia de que cosméticos são produtos estritamente femininos (FONSCECA, 2015).

Conhecer o mercado de consumo cosmético masculino, bem como a mudança na relação do homem com a cultura que o cerca, torna-se necessário para que novos produtos sejam desenvolvidos, respeitando sua individualidade e, principalmente, as conquistas coletivas das mulheres (FONSCECA, 2015). Além disso, há uma importância em compreender quais são as situações que afastam o homem da utilização de cosméticos, mesmo produtos essenciais como protetor solar (MCKENZIE et al., 2019).

Além do conhecimento mercadológico e sociocultural é necessário entender que as peles de ambos os sexos biológicos se comportam de forma diferente. O órgão em questão tem a ação de transformar a testosterona em diidrotestosterona, forma ativa do hormônio, e a secreção sebácea está intimamente ligada com essa característica. Os homens, portanto, apresentam uma maior secreção sebácea, entre outras questões relacionadas à fisiologia que já estão bem descritas na literatura (MIZUKOSHI, AKAMATSU, 2013).

Entretanto, é inegável a contribuição do meio para com as possíveis alterações e agressões que a pele possa receber (KRUTMANN et al., 2017). Nesse contexto, mais do que apenas questões genéticas estão relacionadas com processos como envelhecimento e até mesmo incidência de câncer de pele. Há uma componente social fortemente atrelada a essa situação, haja visto que o uso de cosméticos também enfrenta uma certa barreira social de acesso (INFANTE, CALIXTO \& CAMPOS, 2016; McKENZIE et al., 2019).

Um dos principais problemas dermatológicos que acometem os homens é a pele oleosa com tendência à formação de comedões. Caracteriza-se por ser uma afecção dos folículos pilossebáceosdoença. Uma das características desses folículos é, justamente, a de ter uma glândula sebácea hipertrofiada e um pelo fino, com deposição de queratina de sebo. A hipersecreção sebácea é o segundo fator fundamental para o desenvolvimento de comedões associada ao primeiro fator citado. O desenvolvimento da glândula sebácea se dá na puberdade, graças à ação de hormônios andrógenos, como a testosterona (NAKAHARA et al., 2015; MCCARTY, 2016). 
O conhecimento de ativos que auxiliem no reequilíbrio hidrolipídico da pele é uma alternativa para que os problemas citados sejam contornados. Determinados óleos essenciais (misturas complexas e voláteis obtidos de partes secretoras das plantas) apresentam, comprovadamente, ações antifúngica, antibacteriana e anti-inflamatória. Melaleuca, lavanda, eucalipto e tangerina são exemplos de plantas que fornecem óleos essenciais com as características citadas (ABE et al. 2003; PAZYAR et al., 2013; SWAMY, SINNIAH, 2015). O conhecimento das propriedades terapêuticas de tais óleos, aliado às técnicas precisas de pesquisa e desenvolvimento de produtos cosméticos, podem auxiliar em formulações para a manutenção das características da pele com tendência acnéica (LERTSATITTHANAKORN et al., 2006). Há falta de estudos na literatura sobre a eficácia clínica e segurança desses óleos essenciais, tanto utilizados isoladamente ou em combinação, sendo importante o seu estudo detalhado.

A utilização de nanoemulsão pode ser uma alternativa para melhorar a estabilidade do óleo essencial, da formulação cosmética, bem como aumentar a penetração do óleo essencial através do estrato córneo.

A pesquisa e desenvolvimento de cosméticos é necessária para que formulações com características físico-químicas e físico-mecânicas favoráveis sejam obtidas, de forma a melhor veicular o ativo, bem como obter formulações mais estáveis, seguras e com sensorial agradável. Assim, no desenvolvimento de uma formulação cosmética, é fundamental a seleção de matérias primas adequadas, compatíveis entre si e com a pele, bem como a padronização dos métodos de produção e realização de testes de estabilidade e avaliação sensorial para garantir a melhor performance do produto.

Apesar de o sensorial ser o primeiro contato do consumidor com o produto e ter influência direta no sucesso de vendas e/ou adesão ao tratamento, a comprovação dos efeitos acaba sendo de grande importância para atingir as expectativas do mercado, bem como garantir a continuidade do uso. Além disso, a comprovação da eficácia é importante, pois é exigida para fins de registro de produtos cosméticos Grau 2 nas agências regulatórias de saúde. (ESTANQUEIRO, 2016).

Podemos ainda correlacionar o sensorial com as características físico-mecânicas das formulações cosméticas (CALIXTO, INFANTE \& MAIA CAMPOS, 2018). Além disso, para a estabilidade física, a reologia tem tido crescente interesse nas indústrias cosmética e farmacêutica, tendo em vista que a consistência e o espalhamento dos produtos devem ser 
reproduzidos de lote para lote, assegurando a qualidade tecnológica do produto acabado (GASPAR, MAIA CAMPOS, 2003; GUARATINI, GIANETI, MAIA CAMPOS, 2006).

Nos últimos anos, houve aumento do foco no desenvolvimento tecnológico de metodologias confiáveis e reprodutíveis para caracterizar a pele e avaliar as respostas da aplicação de um produto. Com essas técnicas, busca-se o conhecimento das alterações da arquitetura celular e tecidual, uma vez que são de extrema importância para avaliar as respostas terapêuticas (BRANZAN et al.,2007).

A microscopia confocal de reflectância a laser tem sido considerada uma ferramenta de extensa aplicação na clínica dermatológica, representando-se como uma revolução no diagnóstico de doenças de pele e avaliação de características cutâneas, por permitir a visualização em nível celular com resolução quase histológica de características celulares e teciduais por um método não invasivo, em tempo real. Essa técnica tem sido muito utilizada em estudos dermatológicos, mas ainda carece de dados, tornando-se necessária para estudos que buscam comprovar eficácia clínica de substâncias ativas de uso em produtos cosméticos (BRANZAN et al., 2007; GONZALEZ, GILABERTE-CALZADA, 2008).

As imagens obtidas pelo microscópio confocal permitem a avaliação de características cutâneas tais como espessura das diferentes camadas da epiderme, identificação de áreas hiperqueratóticas na epiderme superficial, na região folicular, aspecto superficial da pele, tamanho e quantidade dos folículos, organização dos queratinócitos, alterações no padrão de pigmentação, quantidade de papilas dérmicas por área, formato dos contornos das papilas dérmicas, tamanho das glândulas sebáceas, e estrutura da rede de colágeno, contagem e tamanho de poros e microcomedões (SAUERMANN et al., 2004; SUGATA et al., 2008; ULRICH et al., 2009; LONGO et al. 2013; WURM et al., 2012,).

Essa técnica pode ser aliada aos aparelhos que utilizam as técnicas de biofísica e de análise de imagem da pele, resultando em dados mais precisos acerca da segurança e eficácia das formulações. As referidas técnicas utilizam vários equipamentos com diferentes princípios físicos e/ou físico-químicos que facilitam a interpretação dos resultados de como determinado produto cosmético pode atuar na pele (OBA et al., 2002, 2002; SMITH et al., 2002; FIROOZ et al., 2012).

A fototoxicidade é definida como uma resposta tóxica de uma substância aplicada ao corpo que aumenta após a exposição subsequente à luz, ou que é induzida pela irradiação da pele após a administração sistêmica de uma substância (OECD, 2004). É uma resposta cutânea 
não imunológica induzida pela luz (dermatite) a um composto fotoativo, e a resposta cutânea é caracterizada por respostas inflamatórias, como eritema e às vezes edema, vesiculação e pigmentação (GASPAR et al., 2013). Alguns óleos essenciais apresentam características fototóxicas e o estudo com diferentes métodos é importante antes dos ensaios clínicos (NATHALIE et al., 2006).

Por outro lado, o estudo com algumas metodologias in vitro pode ser limitado pela maior sensibilidade e pela avaliação direta em cultura de células (MACIEL et al., 2019). É importante utilizar outras metodologias usando modelos ex vivo e/ou in vivo, por exemplo, para entender melhor o comportamento de alguns compostos nos diferentes modelos de pele. A substância pode apresentar citotoxicidade de acordo com a concentração, mas a penetração através do estrato córneo pode ser limitada. Dessa forma, a utilização de metodologias não invasivas como a espectro microscopia Raman para estudar a penetração de óleos essenciais no estrato córneo é importante e necessária uma vez que os estudos para compreender o comportamento na barreira cutânea desses compostos são escassos.

Estudos in vivo em pele humana demonstram que a luz ultravioleta gera a maioria dos radicais, seguida pela irradiação visível (VIS) e infravermelha próxima (NIR). A irradiação VIS e NIR penetra mais profundamente na pele do que a luz ultravioleta, aumentando a formação de espécies reativas de oxigênio nas camadas mais profundas da pele. Portanto, a proteção solar deve ser adaptada ao tipo de pele e ao conhecimento de como melhorar o fotoprotetor para proteção além da radiação UV (MEINKE et al., 2011). Pensando no público masculino que apresenta barreiras ao uso de protetor solar, a proteção precisa ser pensada para além do UV, agregando atividade antioxidante que reduzam os impactos dos demais comprimentos de onda e da ausência de hábitos cosméticos.

Em síntese, o presente trabalho apresenta como contribuição a avaliação clínica a nível celular, por técnicas objetivas não invasivas, das alterações cutâneas decorrentes da acne e fotoenvelhecimento em homens, podendo fornecer subsídios científicos na elucidação das características desse tipo de pele e para o desenvolvimento de intervenções clínicas adequadas. Além disso, aplica e padroniza técnicas que envolvem tecnologia avançada na avaliação de eficácia em nível celular de produtos cosméticos à base de óleos essenciais e fotoprotetores, associada com avaliações objetivas e subjetivas para demonstrar os efeitos de hábitos e da aplicação de produtos cosméticos. O estudo contribuirá também na comprovação da evolução da relação do homem com a indústria cosmética ao longo dos anos, além de apresentar as influências do marketing dentro da perspectiva de consumo desse mercado consumidor. 


\subsection{A PELE, SUAS CAMADAS E SUAS CARACTERÍSTICAS}

A pele é o maior órgão do corpo humano, sendo responsável pela termorregulação, defesa, percepção sensorial e proteção contra agressões externas. É também responsável por reduzir perdas de água e nutrientes para o exterior. Esse órgão apresenta uma renovação constante e é dividido em diferentes camadas e subdivisões com diferentes finalidades para cada uma. Podemos dividi-la basicamente em epiderme e derme, porém mesmo essas camadas apresentam subdivisões importantes para a compreensão da fisiologia da pele e para o estudo da eficácia de cosméticos (JUNQUEIRA et al., 2013).

De fora para dentro, a primeira delas é a epiderme, uma camada com diferentes espessuras de acordo com a região do corpo. Um dos fatores que influenciam essa maior espessura é o atrito, por exemplo, palmas dos pés apresentam maior espessura da epiderme, especialmente por apresentar maior espessura da camada córnea (JUNQUEIRA et al., 2013).

A epiderme se renova de dentro para fora, da camada basal para o estrato córneo. Na basal, as células são menores e há uma maior proliferação. Conforme a epiderme vai se renovando, as células aumentam de tamanho e vão tornando-se mais especializadas até a apoptose - morte celular programada - ocorrer levando à formação da camada córnea, composta basicamente de células mortas, lipídeos, proteínas e água. A epiderme é constituída por um epitélio estratificado pavimentoso queratinizado (células escamosas em várias camadas). A célula principal é o queratinócito que produz a queratina, uma proteína resistente e impermeável responsável pela proteção (JUNQUEIRA et al., 2013).

Como dito anteriormente, a epiderme é a principal interface entre o hospedeiro e o meio ambiente. Evidências substanciais indicaram que as células da epiderme desempenham um papel ativo na geração e expressão de respostas imunes protetoras e reações imunopatológicas, não estando apenas relacionados com proteção física do meio externo (ALBANESI et al., 2005). Nos queratinócitos em repouso, os mediadores imunes são quase indetectáveis. Contudo, após estimulação por luz ultravioleta, por exemplo, podem ser observados alérgenos, agentes microbiológicos e, acima de tudo, citocinas, um aumento significativo de mediadores imunomoduladores in vitro e in vivo. O resultado de muitas reações cutâneas depende da interferência entre células T infiltrantes e queratinócitos, sendo essas reações mais observadas em modelos in vivo do que in vitro (SAND et al., 2018). Dessa forma, é importante ressaltar que a epiderme apresenta uma função muito pautada também na defesa celular em vários níveis. 
Outra célula encontrada na epiderme é o melanócito. Essa célula é responsável pela produção de melanina que será deposita nos queratinócitos, sendo caracterizada por ser dendrítica. As cores que vemos na pele e seus anexos são em grande parte determinadas por essas células. Além de carotenóides e hemoglobina, a melanina é o principal contribuinte para a pigmentação. Existem dois tipos principais de melanina: a feomelanina (vermelha/amarela) e eumelanina (marrom/preta). Os grânulos contendo melanina são conhecidos como melanossomas e são exportados dos melanócitos para os queratinócitos adjacentes. Como resultado, diferenças de pigmentação podem surgir da variação no número, tamanho, composição e distribuição dos melanossomas, enquanto os números de melanócitos geralmente permanecem relativamente constantes. A produção de melanina sofre influência de agentes externos com a exposição aos raios UV (LIN \& FISCHER, 2007).

A epiderme não possui vascularização própria, uma forma de reduzir a penetração de agentes externos à circulação sistêmica. Os nutrientes e oxigénio chegam à epiderme por difusão a partir de vasos sanguíneos que se localizam na derme (JUNQUEIRA et al., 2013).

A epiderme pode ser dividida em algumas camadas:

- Basal: está na junção derme-epiderme, sendo constituída por células cúbicas e pouco diferenciadas, que produzem pouca queratina, mas se dividem continuamente. Essa camada é importante porque a divisão e posterior diferenciação para camadas mais superficiais é a base para o processo de renovação da epiderme que leva cerca de 14 a 28 dias;

- Espinhosa: nessa camada as células começam a produzir mais queratina do que as da basal. Começam a formar junções celulares umas com as outras, os chamados desmossomas e tight junctions. São essas junções que dão o aspecto de espinhos da camada e serão importantes para a formação do estrato córneo posteriormente;

- Granulosa: são células achatadas, com grânulos de queratina e produzem também outras proteínas. Apresentam um volume maior, tendo em vista que estão produzindo mais proteínas e já na fase final de renovação celular. Nessa fase também há aumento na produção de lipídeos intra e extracelulares que serão importantes para a formação da camada córnea;

- Lúcida: é formada por células achatadas, hialinas, eosinófilas por conta de muitos grânulos proteicos. A maior parte já está em processo apoptótico;

- Camada córnea: é uma das partes mais importantes para o estudo da eficácia e segurança de cosméticos. Formada basicamente por células achatadas, sem núcleo e com grande 
quantidade de filamentos de queratina. Além disso, apresenta uma grande quantidade de lipídeos e água. Esses lipídeos podem ser provenientes do processo de renovação celular e/ou secretados pelas glândulas sebáceas. É nessa camada que se forma, por exemplo, o microrrelevo cutâneo, importante fator para entendermos a ação dos cosméticos.

Após o processo de renovação cutânea a pele apresenta um determinado microrrelevo, formado por picos e vales devido à deposição de células mortas, proteínas e lipídeos. Quando a luz incide na pele, se o microrrelevo apresenta-se muito irregular, com grande diferença entre os picos e vales, ela tende a se dispersar mais, tornando a pele opaca e com aparência áspera. Quando reduzimos essa diferença através do uso de cosméticos, seja por ação esfoliativa ou por efeito de maquiagem, a luz se dispersa menos, tornando a aparência mais viçosa e saudável. Esse aspecto é importante para a compreensão de que cosméticos devem atuar na camada córnea e, em alguns casos, nas camadas mais superiores da epiderme viável (PIÉRARD et al., 2003). Processos como hidratação ou formação de filme em cosméticos também podem auxiliar para que o microrrelevo seja melhorado (GIANETI et al., 2013; DE MELO \& MAIA CAMPOS, 2019). Ainda, o estrato córneo é importante para reduzir a penetração de substâncias, o que esperamos de fotoprotetores, por exemplo (WEIGMANN et al., 2005).

Outro aspecto interessante da fisiologia da epiderme - mais especificamente na junção com a derme - é a formação de papilas que são invaginações no tecido epidérmico com a capacidade de aumentar as trocas entre a derme e a epiderme, tendo em vista que aumentam a área superficial. Uma característica consistente da pele envelhecida e fotoenvelhecida é o achatamento da junção epidérmico-dérmica, evidenciado em cortes histológicos com o desaparecimento das projeções papilares. Cada papila apresenta uma alça capilar nutritiva única e o achatamento, como esperado, reduz as trocas entre os tecidos. A estrutura das papilas é sustentada por vários tipos diferentes de colágeno de acordo com a posição anatômica (SAUERMANN et al., 2002). Um esquema dessa camada está apresentado na figura 1.

A outra camada da pele é a derme, com presença principalmente de fibroblastos que são células responsáveis pela produção de colágeno que dão sustentação a pele e a elastina que auxilia na elasticidade da pele. É responsável por cerca de $90 \%$ da espessura cutânea. É nesta camada que o padrão predominante de fibras de colágeno determina a tensão característica e as rugas da pele. As fibras proteicas da derme deterioram-se com a idade e não são substituídas; consequentemente, em pessoas idosas a pele apresenta rugas e flacidez, porém esse processo não está só relacionado ao colágeno, mas a mudanças nos padrões de proporções entre queratina e querato-hialina produzidas na pele (JUNQUEIRA et al., 2013). A exposição solar 
desprotegida também pode afetar o padrão de organização das fibras de colágeno, reduzindo sua qualidade e levando a quadros de elastose solar (WLASCHEK et al., 2001). É constituído por elementos fibrilares, como o colágeno e a elastina e outros elementos da matriz extracelular, como proteínas estruturais, glicosaminoglicanos, íons e água (JUNQUEIRA et al., 2013).

Figura 1: Representação esquemática das camadas da epiderme

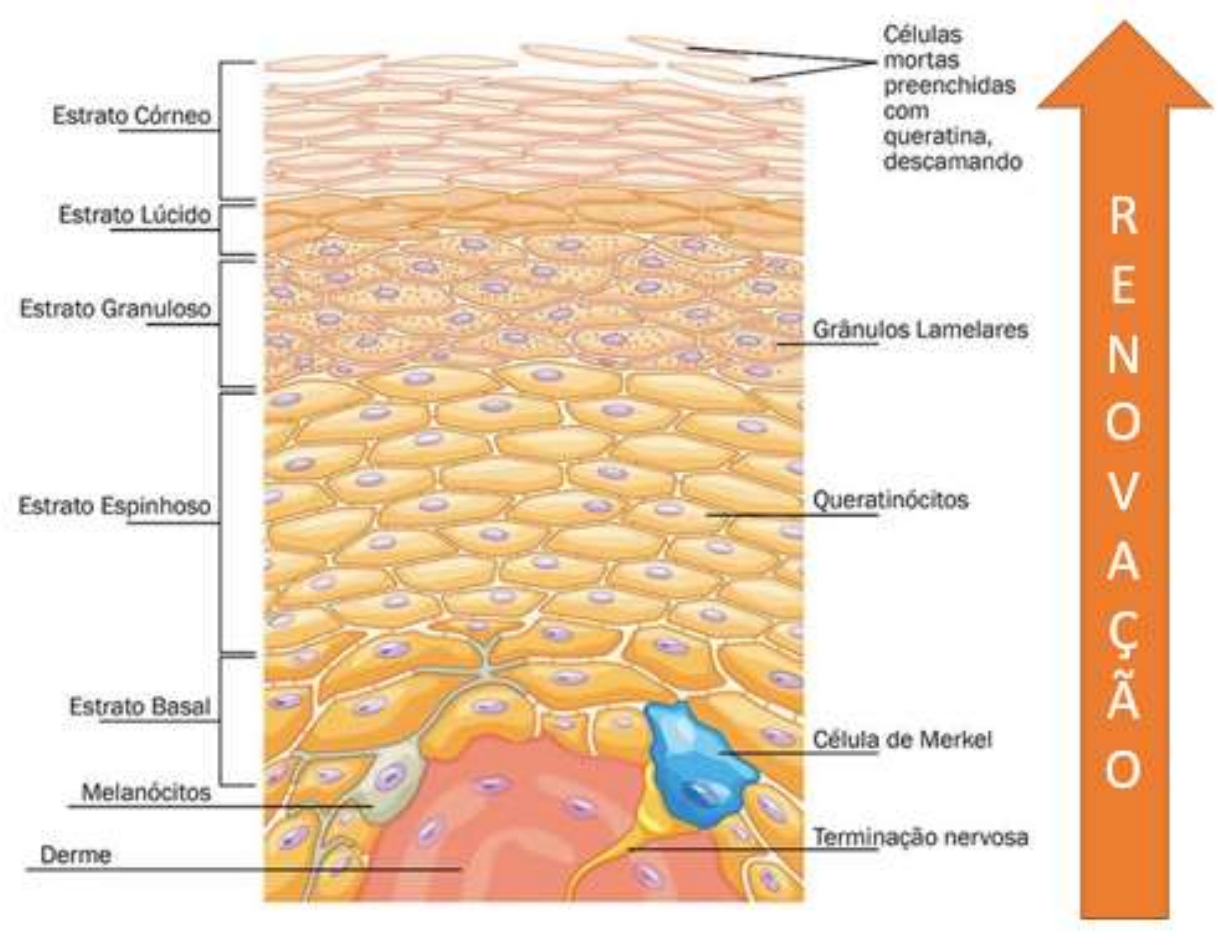

Fonte: Adaptado de JUNQUEIRA \& CARNEIRO, 2013

A derme é subdividida em duas camadas: a camada papilar em contato com a epiderme, formada por tecido conjuntivo frouxo, e a camada reticular, constituída por tecido conjuntivo denso não modelado, onde predominam as fibras colagenosas (HARPER \& GROVE, 1979). Entretanto, é na camada papilar que ocorrem os principais danos associados às fibras de colágeno da pele com relação à exposição solar desprotegida (WLASCHEK et al., 2001). É também na derme que se localizam os vasos sanguíneos que nutrem a epiderme, vasos linfáticos, nervos e os órgãos sensoriais a eles associados como órgão de Ruffini - sensíveis ao calor - e Células de Merckel - sensíveis a tato e pressão, essa mais presentes na junção com epiderme (JUNQUEIRA et al., 2013).

A classificação da hipoderme como parte da pele tem se tornado controversa na literatura científica nos últimos anos, tendo em vista seu caráter metabólico e de armazenamento. Ainda, o tecido adiposo pode ser dividido em duas camadas distintas: hipoderme e tecido celular subcutâneo, pois são camadas que apresentam anatomia, histologia 
e metabolismo completamente distintos. É constituída por tecido adiposo que pode armazenar gordura e onde ocorre a conversão de hormônios esteroides que podem atuar nas glândulas sebáceas (DA CUNHA et al., 2014).

Ainda pensando na estruturação da pele é preciso levar em consideração também a estrutura folicular pois essa tem ganhado muita atenção nos últimos anos devido à função de reservatório de nanopartículas, por exemplo (LADEMANN et al., 2008). O tamanho e a quantidade de folículos variam de acordo com o sítio anatômico. A região facial, por exemplo, cresce menos do que as demais áreas do corpo durante o desenvolvimento do indivíduo. Dessa forma, a densidade folicular nessa região é muito maior, sendo de importância para a avaliação clínica de cosméticos, por exemplo (OTBERG et al., 2014). É nessa região que o anexo - pelo ou cabelo - atravessa toda a estrutura da pele, sendo colonizada por bactérias e fungos de importância médica como a Cutinobacterium acnes, relacionada à acne (DRÉNO et al., 2018). É por essa estrutura que há a secreção sebácea e podem ocorrer processos como a hiperqueratinização, relacionada a acne (JUNQUEIRA et al, 2013).

Dentro da estrutura do aparelho folicular, a parte superior, o acroinfundíbulo, é coberta por uma camada córnea normalmente estruturada, que pode ser considerada uma barreira. Contudo, na parte inferior do infundíbulo, a parede apresenta poucos ou poucos corneócitos diferenciados e deve ser considerada como altamente permeável (SCHAEFER \& LADEMANN, 2001).

Junto da estrutura do folículo há a presença da glândula sebácea que é responsável pela produção de sebo que será secretado, continuamente, até a região infundibular, mais superior, próximo à junção derme-epiderme. São classificadas como holócrinas, ou seja, que excretam para o exterior o seu conteúdo. As glândulas sebáceas encontram-se mais próximas da hipoderme e não são alvo de produtos cosméticos, sendo especialmente importantes para a produção de sebo que possui atividade antioxidante e antibacteriana. O sebo secretado no infundíbulo pode sofrer alguma modificação bioquímica causada por microrganismos e enzimas e depois é secretado, aos poucos por capilaridade, à superfície da pele. Esse processo é importante para entendermos como cosméticos atuam regulando o sebo (JUNQUEIRA et al., 2013; ABRAMOVITS \& GONZALEZ-SERVA, 2000). 


\subsection{TÉCNICAS DE BIOFÍSICA E IMAGEM PARA AVALIAÇÃO DA PELE}

Para a compreensão da saúde da pele, bem como da eficácia de produtos cosméticos e da ação de agentes externos, medidas objetivas baseadas em princípios biofísicos foram desenvolvidas. As técnicas serão apresentadas de acordo com sua função.

A medida dos níveis de água da primeira camada da pele se dá através do princípio da capacitância. Esse princípio se vale da passagem de uma corrente elétrica através do estrato córneo de baixa potência. A presença de água facilita a passagem dessa corrente, enquanto a sua ausência dificulta tal evento. Dessa forma, valores arbitrários são obtidos de acordo com essa medida (WERNER, 1986).

Nossa pele perde água constantemente para o meio e essa medida instrumental vale-se do princípio de difusão de Fick. Esse princípio baseia-se em que a água vai de um meio mais concentrado para um menos concentrado. É expressa por gramas por metro quadrado e por hora. O estrato córneo saudável apresenta água em sua composição e a perde em uma taxa não muito constante para o meio, porém quando a barreira da pele está comprometida essa perda é maior e acaba afetando até mesmo partes da epiderme viável (MÜNDLEIN et al., 2008).

Quando há a aplicação de produtos tópicos na superfície da pele, há alterações nas imagens de microscopia confocal tanto no estrato córneo, quanto na camada granulosa. No estrato córneo é possível observar o aumento do brilho e redução da distância dos sulcos, sendo mais proeminente em produtos cosméticos com características filmógenas (DE MELO \& MAIA CAMPOS, 2019). Ainda, é possível observar o intumescimento da camada córnea, aumentando sua espessura e se acoplada de espectroscopia Raman é possível observar a relação de água ligada ao fator natural de hidratação (CHOE et al., 2017). Manfredi et al. (2013) descreveram também que a camada granulosa apresenta um maior brilho interqueratinócito, com aumento no volume celular após a aplicação de produtos cosméticos. Essa metodologia ainda está sendo melhorada para a aplicação em novos estudos para a eficácia de produtos cosméticos.

Uma variedade de técnicas tem sido usada para medir os níveis de sebo na pele, incluindo classificação visual, extração com solvente, papel absorvente, argila de bentonita, fita ou filme absorvente de lipídios, técnicas fotométricas e absorção gravimétrica. Um dispositivo amplamente utilizado é o Sebumeter ${ }^{\circledR}$, que é uma técnica fotométrica. Com esse dispositivo, os óleos na superfície da pele são absorvidos em um filme polimérico, tornando o filme

transparente. À medida que mais óleo é absorvido, o filme se torna mais transparente e a 
medição pode ser usada para determinar a oleosidade da pele. É comumente relatado que a saída do dispositivo se correlaciona diretamente com o nível de sebo na pele nas unidades de $\mu \mathrm{g} / \mathrm{cm}$ (CROWTHER, 2016). Leite e Maia Campos (2020) utilizaram essa técnica para analisar o sebo presente na região capilar.

Essa medida biofísica vale-se do mesmo princípio para a citada anteriormente, entretanto a fita absorvente lipídica do Sebumeter ${ }^{\circledR}$ coleta todo o sebo presente nas camadas superiores da pele, incluindo o reservatório folicular e a superfície interfolicular da pele. Já o Sebufix ${ }^{\circledR}$, outra técnica baseada em biofísica, absorve apenas o sebo presente na parte superior do infundíbulo, sendo uma ótima forma de analisar a liberação de sebo para a superfície da pele em tempo real. Ambas as técnicas podem ser utilizadas de forma complementar para melhorar a análise do sebo (DOBREV, 2007). Maia Campos et al. (2019) mostraram em seu estudo que a quantidade de sebo produzida varia de acordo com a região facial e com o tipo de pele, sendo importante delimitar as regiões de estudo.

Um método para quantificar a topografia da pele humana é desejável porque torna-se possível mensurar os efeitos que os tratamentos cosméticos têm no relevo cutâneo. Perfilômetros são instrumentos de ponta que geram um traço do contorno de uma superfície, convertendo o movimento vertical da ponta de uma ponta em sinais elétricos à medida que a ponta é movida pela superfície. Gráficos da saída elétrica de um perfilômetro em função do tempo ou deslocamento horizontal (comprimento de varredura) são frequentemente chamados de perfis de superfície (perfilogramas), ou seja, essas técnicas valem-se de princípios baseados na cartografia. De uma forma simples, a perfilometria é uma forma de cartografar o microrrelevo cutâneo, sendo útil para observarmos eficácia de cosméticos, formação de filme e dispersão na superfície da pele. Na pele, esses perfis representam vistas em corte transversal do limite superior da pele. Os parâmetros de rugosidade, quantidades físicas que podem ser interpretadas geometricamente a partir dos perfis de superfície, são usados para quantificar as medições da superfície (COOK et al., 1982).

Há diferentes tipos de ultrassons utilizados para a avaliação das características morfológicas da pele. Um deles é o DermaScan que utiliza um ultrassom de $20 \mathrm{MHz}^{\circledR}$.

Com esse aparelho é produzida uma imagem transversal da pele humana com uma resolução axial de $80 \mu \mathrm{m}$ e resolução lateral de $200 \mu \mathrm{m}$ com um transdutor de foco preciso. A onda ultrassônica é parcialmente refletida na fronteira entre estruturas adjacentes e produz ecos de diferentes amplitudes. A intensidade dos ecos de reflexão é avaliada pelo microprocessador e é visualizada como uma imagem em modo B bidimensional com código de cores. A amplitude 
média dos ecos em uma área definida da imagem é conhecida como ecogenicidade, que pode ser objetivamente medida com a análise de imagem assistida por computador. A velocidade do ultrassom na pele foi fixada em $1.580 \mathrm{~m} / \mathrm{s}$.

A imagem típica do ultrassom obtida de uma pele saudável é composta por três camadas de ecogenicidade diferente. A camada mais externa é altamente ecogênica, fina, e está correlacionada com a epiderme. Por baixo, há uma camada dérmica, que é menos ecogênica do que a epidérmica e contém muitos ecos diferentes de várias intensidades. Nessa região podemos subdividir entre derme papilar e derme reticular. A última camada está relacionada ao tecido subcutâneo não ecogênico e onde o aparelho perde resolução.

Essa metodologia é especialmente importante para a compreensão das redes de colágeno da pele que se localizam na derme (POLANSKA et al., 2013). Pellacani \& Seidenari (1999) observaram que essa metodologia apresenta algumas limitações como por exemplo, peles com processos inflamatórios podem ter a medida de ecogenicidade atrapalhada, já que o processo inflamatório envolve o acúmulo de água - edema - que pode atrapalhar na resposta da técnica. Eles observaram, ainda, que a ecogenicidade varia de acordo com a região do corpo e há variação nos sítios anatômicos da face.

Mercurio et al. (2016) utilizaram a técnica para a observação de dano causado pela exposição solar desprotegida. É possível observar uma hipoecogenicidade - sinal de baixa intensidade - na camada superior da derme. Esse sinal clássico de fotoenvelhecimento foi observado também por outros autores (SHIRATA et al., 2019; NAKAHIGASHI \& SUGAI, 1996; GNIADECKA \& JEMEC, 1998).

A Microscopia Confocal de Refletância a laser é uma técnica muito importante e inovadora para avaliar as características morfológicas e estruturais da pele, principalmente nas camadas da epiderme, estrato córneo e derme papilar, perdendo resolução na derme reticular. Este equipamento permite a determinação de características e alterações morfológicas e estruturais em tempo real da epiderme após a aplicação de uma formulação tópica, por exemplo (DE MELO \& MAIA CAMPOS, 2019). É possível utilizar essa técnica para analisar a espessura das camadas, avaliar área das células, número de células, pigmentação, padrão de organização celular, morfologia da pele, estruturas de colágeno presentes na derme. É uma ferramenta muito útil para a avaliação da eficácia de cosméticos e para estudar a influência dos hábitos na saúde e qualidade da pele, uma vez que é possível quantificar os danos causados pela exposição solar desprotegida (LONGO et al., 2013). 
As espécies reativas de oxigênio (EROs) são essenciais para funções biológicas, como a cadeia respiratória, transferência de sinal e resposta imune. No entanto, em excesso, poderão ocorrer efeitos negativos como o estresse oxidativo (LOHAN et al., 2015).

Esse estresse é agravado após exposição solar desprotegida e/ou efeitos de poluição na pele. Sabe-se, por exemplo, que a exposição às radiações UVA, visível e infravermelha aumentam a produção de radicais livres na pele. A radiação UVB acaba aumentando também, porém por um mecanismo mais indireto, envolvido no processo de modulação inflamatória (MEINKE et al., 2011). Os efeitos dessa exposição desprotegida na pele e nos diferentes modelos de estudo já estão bem estudados, porém ainda é necessário estudar mais sobre o fator de proteção de radicais livres das formulações fotoprotetoras (ZASTROW et al., 2017). É preciso entender, também, as variações possíveis em peles de fototipos mais altos, as evidências mais recentes demonstram que há diferenças em como cada radiação estimula cada tipo de pele (ALBRECHT et al., 2019).

Para essa finalidade podemos utilizar o a ressonância eletroparamagnética (EPR), que é uma metodologia não invasiva baseada na absorção da radiação de micro-ondas por substâncias paramagnéticas em um campo magnético estático aplicado externamente. A absorção de microondas ocorre quando a radiação aplicada corresponde à diferença de energia entre os estados de rotação de um elétron não emparelhado. Substâncias paramagnéticas contêm elétrons não emparelhados, permitindo a detecção de radicais livres e espécies reativas de oxigênio na pele (ELPELT et al., 2019).

Radicais semiestáveis podem ser usados para investigar a capacidade de eliminação de radicais da pele. Para esta técnica, o marcador de rotação é aplicado no antebraço ou no modelo de pele escolhido para a realização do estudo e a diminuição do sinal EPR é monitorada ao longo do tempo. Os radicais livres reagem com a sonda de rotação e a reduzem, reduzindo o sinal gerado. Se uma formulação apresenta um bom sistema antioxidante, após a exposição aos radicais livres é esperado que haja uma redução menos perceptível no marcador de rotação, tendo em vista que o antioxidante reage com os radicais livres (LOHAN et al., 2015; ELPELT et al., 2019).

Para estudos de eficácia de cosméticos e da análise das alterações cutâneas ocasionadas pela exposição solar desprotegida são necessárias imagens de alta de resolução dos participantes. Entretanto problemas como padronização de iluminação e posição são comuns para esse tipo de estudo. Aparelhos de alta resolução de imagem utilizando iluminação LED e posição padronizadas são desejados para que possamos melhorar a forma como analisamos a 
eficácia dos cosméticos. Ainda, com essa tecnologia, é possível analisar o número de poros, profundidade de rugas e padrão de pigmentação, transformando dados qualitativos em quantitativos (MAIA CAMPOS et al., 2019).

Com essas tecnologias é possível estudar vários parâmetros relacionados às características da pele, sendo interessante para a aplicação com relação às diferenças biofísicas, morfológicas e estruturais entre pele masculina e feminina, por exemplo.

\subsection{DIFERENÇAS BIOFÍSICAS, MORFOLÓGICAS E ESTRUTURAIS ENTRE A PELE MASCULINA E FEMININA}

É inegável que há diferenças fisiológicas entre as peles masculina e feminina já bem retratadas na literatura e bem entendidas nos campos médico e farmacêutico. Essas diferenças resultam em alterações estruturais quando comparamos ambos os sexos. Homens, por exemplo, apresentam barba na região da face, o que implica não apenas em uma fisiologia diferente, mas hábitos como o barbear que também afetam a saúde e qualidade da pele (COWLEY, VANOOSTHUYZE, 2012). Aqui já podemos começar a trabalhar a distinção entre as ideias de sexo biológico, sexualidade e identidade de gênero e como é preciso entender essas diferenças para que os estudos sejam mais do que apenas a polarização homem/mulher.

Em termos simples, o sexo biológico diz respeito às características biológicas que a pessoa tem ao nascer e isso é dependente de fatores cromossômicos que levam à formação de genitália, diferenças na composição hormonal, entre outros. Importante ressaltar que a questão hormonal pode se alterar durante a vida do indivíduo, uma vez que na puberdade há o aumento de testosterona para homens e progesterona para mulheres (DE JESUS, 2012). Em um primeiro momento, isso infere que a pessoa possa nascer macho, fêmea ou intersexual.

Há uma relação direta na questão do sexo biológico, composição hormonal e características fisiológicas da pele. O sexo masculino, por exemplo, por possuir uma quantidade maior de testosterona circulante apresenta uma produção maior de sebo pelas glândulas sebáceas, uma vez que o mecanismo é altamente dependente de hormônios esteroides. Isso já está bem descrito na literatura desde os anos 60 (POCHI et al, 1965). Entretanto, a testosterona - especialmente sua forma ativa 5 $\alpha$-Di-hidrotestosterona - é importante para a biologia do folículo piloso, como aumento da espessura do folículo e do início do surgimento de barba. Essas características sexuais secundárias são importantes para a compreensão da fisiologia - e das patologias - da pele masculina (DEPLEWSKI \& ROSENFIELD, 2000). 
Como há uma relação direta da concentração de hormônios circulantes com as características da pele e esses variam durante a vida do indivíduo fica fácil elucidar que a idade também seja um fator importante para a compreensão das variações fisiológicas que ocorrem durante a vida do indivíduo de sexo masculino. Essa informação é necessária, porém não suficiente, para entendermos, por exemplo, o processo de envelhecimento cutâneo masculino ou a perda de cabelos (alopecia androgenética) (LEVEQUE et al, 1984). Não é suficiente pois há fatores relacionados à cultura, hábitos e identidade de gênero que afetam esse processo, sendo abordados em um momento futuro desta tese.

Com relação às medidas biofísicas e de imagem da pele para avaliar as características hidrolipídicas, morfológicas e estruturais - focos dessa tese - há uma variedade de estudos comparando peles masculina e feminina, além da variação dos parâmetros com as diferentes idades. LUEBBERDING, KRUEGER \& KERSCHER (2013) mostraram em seu estudo com 300 participantes alemães do sexo masculino e feminino (150 de cada), com idades variando entre 20 a 74 anos divididos em 5 grupos (30 homens e 30 mulheres em cada grupo), as variações no $\mathrm{pH}$, perda transepidérmica de água (TEWL), conteúdo aquoso do estrato córneo e sebo superficial. Foi observado que mulheres apresentam uma maior perda transepidérmica de água entre as idades de 30 a 49 anos tanto para a região frontal quanto para o antebraço. Também foi observado maior valor de $\mathrm{pH}$ na região do queixo para as participantes do sexo feminino em todas as etapas da vida e um maior valor de sebo superficial para os participantes do sexo masculino, o que pode estar correlacionado, uma vez que a secreção sebácea tem relação com a formação do manto ácido da pele.

Com relação à função barreira da pele há certa controvérsia na literatura na afirmação generalista de que indivíduos do sexo masculino apresentarem sempre um maior valor para esse parâmetro. Isso porque há uma dependência de parâmetros fisiológicos como localização anatômica, hábitos cosméticos, idade, cor da pele, patologias cutâneas e até localização geográfica do participante. Dessa forma, o entendimento para esse parâmetro precisa ser mais individualizado e pensado além do sexo biológico, com forte influência de fatores como o uso de cosméticos, foco que será discutido com maior embasamento ao longo desse estudo (DARLENSKI \& FLUHR, 2012). Enquanto no estudo de 2013 conduzido pelo grupo alemão há uma maior perda transepidérmica observada à pele feminina, em outro estudo iraniano foi observado o contrário, com maior perda transepidérmica associada aos participantes do sexo masculino (FIROOZ et al., 2012). 
Man et al. (2009) apresentaram em seu estudo, com população chinesa, que o conteúdo de sebo, o pH da superfície da pele e a hidratação do estrato córneo variam com a idade, sexo biológico e sítios anatômicos. Estas alterações, especialmente o conteúdo de sebo, estão correlacionadas com a idade. Esse resultado é interessante porque aparentemente está relacionado com o conteúdo superficial de sebo, porém também é outro parâmetro em que observamos grande divergência na literatura atual. Bailey et al. (2012) relataram que o pH da pele é mais baixo (mais ácido) nos participantes do sexo masculino, mas um estudo realizado por Zlotogorski (1987) mostrou que o pH da pele não estava correlacionado com o sexo biológico. No estudo de Luebberding (2013) apresentado anteriormente, o pH da pele foi maior nas bochechas em ambos os sexos, se comparado com os demais sítios anatômicos, porém não significativo entre os grupos de diferentes sexos. Ainda, resultados de um estudo de Wilhelm et al. (1991) não demonstraram diferença nos valores de $\mathrm{pH}$ entre sexo masculino e feminino na maioria das regiões anatômicas.

Em outro estudo, Luebberding, Krueger \& Kerscher (2014a) apresentaram um desenho experimental similar ao primeiro citado, porém comparando com relação às características mecânicas da pele dos participantes do estudo. Os resultados mostram que a capacidade elástica da pele para se recuperar após a distensão é mais fortemente afetada pelo processo de envelhecimento do que pela firmeza da pele. Além disso, os resultados mostram que as propriedades mecânicas mudam diferentemente em participantes do sexo masculino ou feminino ao longo da vida e que a pele feminina é menos distensível, mas tem maior capacidade de se recuperar após o alongamento quando comparada à pele masculina. O estágio anterior à menopausa pode causar uma diminuição acelerada da elasticidade da pele em mulheres, reforçando que as diferenças biológicas estão relacionadas com a concentração e a variação de hormônios circulantes.

Em outro estudo do mesmo grupo de pesquisa foram analisados 200 participantes dos sexos masculino e feminino. O estudo verificou o aumento progressivo dos pés de galinha e das linhas da testa e glabelas com o passar da vida. O maior aumento na gravidade das rugas é encontrado a partir dos 50 anos. Vale lembrar que esse estudo foi realizado na Alemanha, na cidade de Hamburgo, com baixo índice UV. Ainda, nesse ponto, as rugas da idade se tornam não só mais profundas, mas também mais amplas, resultando em um volume maior e, portanto, em maior visibilidade clínica. Nesse estudo foi observado que os homens desenvolvem rugas mais cedo e mais proeminentemente do que as mulheres, especialmente as linhas da testa, que 
já são marcadas nos indivíduos do sexo masculino na faixa dos 20 anos (LUEBBERDING, KRUEGER \& KERSCHER, 2014b).

Lasagni \& Seidenari (1995) mostraram em seu estudo que a pele masculina se caracteriza por ter uma maior espessura, com menor razão de ecogenicidade do que a feminina quando analisaram as bandas obtidas na região da derme. Espera-se, portanto, uma derme mais espessa, porém com menor densidade de colágeno para o público masculino. As autoras também frisam a importância de outros estudos levando em consideração o hábito de vida dos participantes de estudos para a compreensão de tais características.

Como mostrado na revisão feita por Rahrovan et al. (2018), vários estudos compararam as propriedades biofísicas da pele entre indivíduos do sexo masculino e feminino. Para alguns parâmetros, os resultados são reprodutíveis, como é o caso do sebo superficial. Esse parâmetro tende a ser maior nos indivíduos do sexo masculino porque o sebo é altamente influenciado pelos hormônios sexuais. Além disso, a pigmentação e a espessura da pele são significativamente maiores para esse mesmo público. Sendo o mesmo observado para as rugas faciais (mais profundas) e a flacidez facial, mas não há diferença significativa na elasticidade da pele entre os sexos. Por outro lado, os resultados de outros parâmetros são conflitantes, o que pode ser devido a diferenças no desenho do estudo, dispositivos de medição, tamanho da amostra, local da medição, condições ambientais e genética, como afirmado pelos autores.

Entretanto, não apenas a biologia pode ser levada em consideração quando pensamos nos parâmetros biofísicos da pele. O hábito do uso de cosméticos influencia diretamente na pela manutenção do equilíbrio hidrolipídico e condições gerias da pele. Esses hábitos estão altamente atrelados a condições sociais que facilitam e/ou atrapalham o acesso e utilização de cosméticos com frequência.

\subsection{AS NORMAS DE MASCULINIDADE, O COMPORTAMENTO DO HOMEM, $O$ USO DE COSMÉTICOS E OS IMPACTOS NA SAÚDE DA PELE}

É interessante observar que os estudos sempre estão levando em questão recortes com relação ao sexo biológico, idade ou até mesmo a posição geográfica. Entretanto há poucos estudos que buscam entender outras variáveis como pele masculina negra e como isso impacta nos parâmetros de biofísica e imagem da pele. Além disso, os estudos sempre abordam sobre as diferenças entre os sexos em relação aos parâmetros de biofísica e imagem da pele ou outros abordam apenas na relação com o consumo direto de produtos, mas há uma falta em relacionar 
esses dois tipos de estudo além de adicionar importantes discussões referentes a normas de masculinidade relacionadas a questões de identidade de gênero.

Simone de Beauvoir, em sua obra "O segundo sexo" de 1967, proferiu a expressão "Não se nasce mulher, torna-se". Aqui podemos utilizar essa expressão para começarmos a entender que a forma como homens e mulheres se comportam enquanto indivíduos sociais estão moldados pela cultura que os cerca. Essa fala representa não apenas a diferença de tratamento para homens e para mulheres em uma sociedade patriarcal, mas também partimos aqui para o entendimento de que identidade de gênero não está totalmente vinculada ao sexo biológico. Ainda, podemos extrapolar e pensar na questão de expressão de gênero. Enquanto identidade de gênero é a percepção que uma pessoa tem de si como sendo do gênero masculino, feminino ou de alguma combinação dos dois, independente de sexo biológico, a expressão de gênero é como a pessoa manifesta publicamente a sua identidade de gênero, por meio do seu nome, da vestimenta, do corte de cabelo, dos comportamentos, da voz e/ou características corporais e da forma como interage com as demais pessoas (GLAAD, 2016). E é aqui que entra a importância do estudo de fisiologia da pele e uso de cosméticos para além de sexo biológico, precisando ser entendida também a expressão de gênero, consumo e posterior impacto na saúde da pele.

Essas discussões podem parecer distantes da discussão sobre as características fisiológicas da pele, mas aproximam-se quando observamos dois aspectos congruentes: a pele como órgão de contato social e como as normas de gênero afetam o uso de cosméticos. $\mathrm{O}$ referido órgão torna-se importante nos contextos sociais e culturais porque é através dele que nos expressamos ao mundo e que conseguimos dividir afetos. Os sentidos cutâneos especialmente o toque - são cruciais ainda não apenas para a sensação, mas também para a emoção. As representações relacionadas ao toque e à dor também fornecem uma base para representações intersubjetivas, influenciando a compreensão do conhecimento sensorial, emocional e mental dos indivíduos (LÖKEN \& OLAUSSON, 2010). Nesse sentindo há também uma grande correlação com os cosméticos, tendo em vista seu grande apelo sensorial e de bemestar.

Um exemplo desse contexto social é o trabalho publicado por McKenzie, Rademaker \& Kundu (2019) onde os autores discutem como papéis de gênero demonstraram influenciar comportamentos relacionados à saúde. Para os autores, a masculinidade é frequentemente associada a comportamentos prejudiciais à saúde, enquanto a feminilidade é associada a comportamentos promotores de saúde. Essa observação também é feita por outros grupos de pesquisa (GALDAS, CHEATER \& MARSHALL, 2005; COURTENAY, 2010; CREIGHTON 
\& OLIFFE, 2010; GRIFFITH et al., 2016). Porém no estudo publicado em 2019, os grupos focais sugerem que os homens americanos evitam a utilização de fotoprotetor por causa da associação de feminilidade com produtos de beleza e têm dificuldade em pedir aos colegas do sexo masculino que ajudem a aplicar o protetor solar, porque viola as normas de contato corporal de homem para homem, reforçando o impacto na saúde da pele dos homens por conta das normas sociais.

Apesar desses achados e da maior incidência de melanoma nos homens (National Cancer Institute), as intervenções de proteção solar raramente se concentram na população masculina, bem como o desenvolvimento de produtos cosméticos. A literatura carece de estudos que correlacionem a relação do público masculino com os produtos cosméticos, bem como os impactos na saúde da pele. Essa relação poderia ainda ser uma das causas responsáveis por tantas variações nos estudos para a compressão das características hidrolipídicas, morfológicas e estruturais da pele comparadas à feminina, uma vez que afasta o homem do uso de cosméticos, afetando parâmetros como TEWL e pH cutâneo, além de poder ter correlação com o fotoenvelhecimento precoce.

\subsection{A SEGMENTAÇÃO DOS PRODUTOS COSMÉTICOS E AS DEFINIÇÕES DE MASCULINIDADE}

A despeito do processo de segmentação, de nada adianta o desenvolvimento de um cosmético altamente tecnológico e personalizado para a o público masculino se ele continua a rejeitar a utilização por conta de uma norma masculina criada socialmente. Nesse sentido, estudar a relação do homem brasileiro com cosméticos é importante porque estamos nos referindo a um dos maiores mercados mundiais (INFANTE, MELO \& CAMPOS, 2018).

Além disso, na realização de testes de eficácia de cosméticos é possível identificar padrões de comportamento no uso desses produtos e como isso afeta diretamente a saúde da pele dos indivíduos. Cumpre ressaltar que o presente estudo é o primeiro com enfoque no público masculino desde o entendimento social do homem, o desenvolvimento de produtos cosméticos, estudos de eficácia, perfil de consumo, a relação do homem com cosméticos e como isso impacta na saúde e qualidade da pele masculina.

Para conseguir driblar essas normas masculinas limitantes ao acesso de uso de cosméticos, as definições do homem precisaram ser revistas. Elas estão altamente correlacionadas com um processo de mudança que tem fina relação com as mudanças sociais vistas no século XX, como por exemplo, a maior ocupação da mulher no mercado de trabalho, 
a visibilidade da comunidade LGBT+ e a mudança em como as famílias se estruturam (MILLER 2005; POMPPER, 2010). Cada vez com menos filhos - ou mesmo sem - os homens puderam começar a ter mais espaço para viver a masculinidade de forma mais variada e menos enraizada em preceitos relativos à normas arcaicas que limitam a experiência sensorial e de consumo. Em outras palavras: mesmo sob a óptica do consumo, as normas de masculinidade anteriormente citadas não são mais tão interessantes.

É interessante ressaltar que a construção social do homem metrossexual tem relação especial com o homem heterossexual, tendo em vista sua maior resistência em aderir ao universo feminino. Originalmente identificado como um fenômeno cultural de destaque na imprensa europeia esse homem foi identificado como heterossexual moderno urbano, bemsucedido, sofisticado e bem-preparado, ou seja, vendendo uma ideia de sucesso cosmopolita. Em junho de 2003, o New York Times publicou um artigo sobre o fenômeno de "homens heterossexuais bem tratados e hidratados" e introduziu pela primeira vez o termo "metrossexualidade" nos EUA (SHUGART, 2008).

O movimento do homem metrossexual tem um apelo principalmente norte-americano e europeu durante os anos 2000. Outras culturas passaram por processo semelhante para a redefinição da relação dos homens com os produtos cosméticos. Um exemplo é a Coréia do Sul que passou por uma ressignificação de toda a sua sociedade desde o início dos anos 2000, tornando-se um dos grandes produtores e consumidores de cosméticos. Entretanto, o país era enraizado em questões masculinas que barravam o avanço desse setor entre os homens. O termo "masculinidade suave" surge como forma de incentivar o homem sul-coreano a consumir mais cosméticos, aceitando normas de autocuidado. Esse tipo de comportamento sofreu grande influência por conta da popularização do K-pop, ritmo musical sul-coreano (MILLER, 2014; RHODE, 2016).

Para o Brasil essa percepção de masculinidade heterossexual menos pautada em preceitos limitantes está presente nos anos 2010 e até hoje configura uma dicotomia interessante. O país configura como o maior mercado de consumo cosmético para o setor masculino (EUROMONITOR, 2019) e mesmo assim ainda apresenta limitações em utilização de cosméticos mais essenciais como fotoprotetor, porém com alta adesão a produtos de higiene pessoal como xampus, sabonetes e perfumes (INFANTE, CALIXTO \& MAIA CAMPOS, 2016). Tribst e Souza (2020) observaram em seu estudo que os homens brasileiros são influenciados pela publicidade para adquirir novos produtos e que a aceitação pela sociedade é algo importante no tocante do consumo de produtos cosméticos pelos homens brasileiros. Dutra 
(2010) observou em seu estudo que o homem brasileiro apresenta dificuldades para falar sobre produtos cosméticos, bem como que a mulher tem um papel interessante para que exista uma maior aceitação do homem para com os produtos cosméticos. Fernandes (2016) observou em seu estudo um crescimento da presença da figura masculina em anúncios publicitários nos anos 2010 no Brasil, reforçando que esse espaço foi construído mais tardiamente no país. Maximo e Leite (2020) observaram que ainda há um espaço de resistência frente ao uso de cosméticos pelos homens brasileiros.

\subsection{O CONSUMO DAS DIFERENTES CATEGORIAS DE PRODUTOS COSMÉTICOS PELOS HOMENS AO REDOR DO GLOBO}

É interessante ressaltar que muitos dos estudos com cunho social, apesar de muito importantes, associam produtos cosméticos todos como uma única categoria, porém é necessário destrinchar melhor essas definições. Os produtos cosméticos são divididos basicamente em produtos de higiene, maquiagem, perfumaria, cuidados com a pele e poderíamos colocar fotoprotetores em uma classificação mais a parte, tendo em vista sua complexidade e importância. A ANVISA divide os produtos cosméticos como Grau 1 ou Grau 2, de acordo com público-alvo (produtos infantis são considerados grau 2) e necessidade de testes de segurança e eficácia.

Nos estudos que associam o consumo de cosméticos ao público masculino brasileiro vemos que há uma certa disparidade de acordo com diferentes categorias. A utilização de produtos de higiene é unânime entre os homens, porém produtos de cuidados com a pele e fotoprotetores ainda apresentam taxas de adesão muito baixas, ficando abaixo dos $30 \%$ para essas categorias (ABIHPEC, 2015; INFANTE, CALIXTO \& MAIA CAMPOS, 2016; DA SILVA et al., 2019). De fato, essa informação nos chama atenção porque a não utilização de fotoprotetores em um país tropical como o Brasil pode ser uma das causas de câncer de pele em maior número entre os homens, como já mencionado anteriormente. Além disso, os efeitos da radiação solar na pele masculina precisam ser entendidos de forma particular, levando em conta uma menor adesão ao uso de protetor solar, bem como de produtos de cuidado com a pele. Há ainda, entretanto, poucos estudos no Brasil que levam em consideração o uso de cosméticos de acordo com cada uma das categorias.

Souiden \& Diagne (2009) mostraram em seu estudo comparando o comportamento de homens franceses e canadenses que ambas as nacionalidades apresentam motivações diferentes. A publicidade e a atratividade são identificadas como tendo um forte impacto positivo no consumo masculino de produtos de higiene pessoal nos dois países, reforçando que há uma 
forte tendência masculina para o consumo de produtos de higiene. Por outro lado, as crenças sociais e as preocupações com a saúde são relatadas como não tendo um impacto significativo no consumo masculino de cosméticos nos dois países, em concordância com outros estudos apresentados. Quanto ao envelhecimento, a consciência da imagem, a situação da compra e o estilo de vida tiveram impacto variável, provavelmente uma variável socioeconômica pode ser percebida. Ainda com relação à população francesa, em outro estudo foi observado que há diferença entre as quantidades de produtos utilizados pelos homens e mulheres, por exemplo, homens usam menos sabonete líquido e mais gel para cabelo do que o público feminino (FICHEUX et al., 2016).

Khan e colaboradores (2017) estudaram os porquês e motivações de homens chineses e paquistaneses consumirem cosméticos. Autoimagem, crenças sociais, assistência médica e envelhecimento são os fatores que mais influenciam os dois países. O estilo de vida está levando os consumidores masculinos chineses a comprar produtos de beleza, mas os consumidores paquistaneses de produtos cosméticos masculinos não levam isso em consideração ao tomar uma decisão de compra. A atratividade física é o fator motivador vital para os usuários paquistaneses de produtos cosméticos masculinos. Vemos que há um reforço da influência da cultura no aspecto de consumo cosmético, ainda que muitas das limitações ao acesso de produtos cosméticos venham de uma cultura que reforça o estereótipo do homem que não deve ter acesso ao autocuidado.

Duarte e colaborares (2019) observaram um panorama parecido ao brasileiro entre os homens portugueses, com cosméticos relacionados a higiene, perfumaria e estilização de cabelo e barba como os mais consumidos. Há uma mudança sendo observada para os consumidores de produtos para os cuidados com a pele, mas ainda não é um mercado tão expressivo como o de produtos de higiene.

Verdugo \& Ponce (2020) observaram em um estudo com amostra de população chilena que os homens estão mais dispostos a utilizar produtos de segmento de luxo do que as mulheres, associando preço à eficácia. Esse segmento mostra-se especialmente atraído pelo setor perfumista.

Alves da Silva Lima (2019) mostrou em seu trabalho com participantes brasileiros, indianos e europeus que os homens ainda pensam no consumo de produtos cosméticos como um tabu e sua percepção sobre o assunto sofre diretamente com a influência de seu ambiente social e cultural, sendo muito perceptível ao homem brasileiro. A maioria dos entrevistados na 
referida pesquisa não admitiu publicamente o consumo de produtos de beleza, apesar de fazêlo, evidenciando um possível barreira cultural a respeito da utilização de produtos cosméticos.

\subsection{O ESTUdO DO CONSUMO DE COSMÉTICOS E A EXPOSIÇÃO A COMPONENTES QUÍMICOS}

Outra importante contribuição de estudos que buscam entender a relação de homens com cosméticos vai além das características mercadológicas e se insere dentro de uma perspectiva de exposição às substâncias químicas presentes nos cosméticos (FICHEUX et al., 2019). Park e colaboradores (2018) mostraram em seu estudo que há diferenças significativas entre o consumo de cosméticos entre homens e mulheres na Coréia do Sul e isso afetaria a exposição aos componentes de produtos cosméticos. O estudo de consumo de cosméticos mostra-se não apenas mercadológico, mas com importantes aspectos para aplicações nas áreas de sociologia, toxicologia, dermatologia e tecnologia farmacêutica.

Produtos cosméticos são diretamente aplicados à pele humana. Enquanto a pele fornece uma barreira protetora através do estrato córneo, certos ingredientes podem penetrá-la e tornarem-se sistemicamente disponível, o que reforça a importância de estudos de penetração de substâncias utilizadas em cosméticos. Alguns produtos cosméticos são aplicados às mucosas, o que pode aumentar a biodisponibilidade ou, no caso dos produtos para os lábios, fornece a oportunidade para ingestão oral. A avaliação de segurança requer conhecimento tanto do perigo intrínseco dos ingredientes contidos no produto quanto bem como dados sobre os níveis de exposição (LORETZ et al., 2005). Aqui é importante ressaltar que conhecer os hábitos de consumo é a principal forma de obtermos informações relevantes sobre essa exposição porque esse conhecimento alia o tipo de produto, frequência de exposição e local de administração. Há pouca informação na literatura relevante para o público masculino em relação ao uso de cosméticos, especialmente para o Brasil, um dos maiores mercados mundiais (INFANTE, CALIXTO, MAIA CAMPOS, 2016).

Para a obtenção de dados das pesquisas citadas anteriormente são utilizadas entrevistas com questionários estruturados, validados ou não, bem como análise do discurso. Essas ferramentas são importantes porque fornecem subsídios para encontrarmos correlações entre aspectos mercadológicos, influências culturais, hábitos e exposição a produtos cosméticos. No processo de segmentação, busca-se encontrar ferramentas que dê subsídios para direcionar o produto ao consumidor e as informações obtidas com essas ferramentas são interessantes para essa proposta (PRESS, SIMMS, 2010). 


\subsection{O MARKETING, O CONSUMO DE COSMÉTICOS E O AUTOCUIDADO MASCULINO}

Há um paradigma que ronda o marketing que diz respeito a ele criar a necessidade ou a necessidade criar a oportunidade (SOLOMONS, 2016). É interessante observar essa perspectiva dentro do mercado cosmético segmentado para o público masculino. Muitas das propagandas reforçam os papéis de gênero na busca de vender mais cosméticos, mas sempre voltados para o setor de produtos de higiene (RIBEIRO \& SILVA, 2017). Mozdzenski \& Aguiar (2016) mostraram em seu estudo sobre algumas publicidades de cosméticos para o público masculino que todas eram focadas no setor de higiene pessoal e tentavam utilizar o humor para trazer um tom mais leve para o consumidor não acostumado com publicidades direcionadas a ele.

Dória (2017) mostrou em seu trabalho que embora tenha se notado uma mudança nas representações de gênero nas peças publicitárias de cosméticos (Natura e Avon) analisadas em seu estudo - principalmente no que diz respeito à representação do homem - ainda existem elementos que remetem aos estereótipos de gênero. Nesse trabalho também foi possível observar que por mais que exista a intenção de propor uma reflexão em torno das diversas maneiras de manifestar a masculinidade, a apresentação das personagens ainda remete à noção do homem tradicional, ou seja, viril, forte, bravo. Esse tipo de análise é importante porque por mais que tenhamos criado a segmentação masculina, ainda parece que ela não reconhece a variedade do "ser homem" - sensível, afetuoso, hétero, gay, trans, dentre outros - reforçando o estereótipo do "homem macho" que é imposto pela tradição e que, na realidade, afasta o consumidor masculino do uso de cosméticos que não sejam de higiene. Se o consumo de perfumaria e produtos de higiene por parte dos homens no Brasil já movimenta mais de 18 bilhões de reais por ano (FORBES, 2020), se as normas de masculinidade não fossem tão limitantes, o setor poderia crescer muito mais com relação à fotoproteção, produtos de cuidados com a pele e até mesmo maquilagem.

Todos esses estudados guiam o entendimento para o público masculino sobre a utilização de cosméticos como algo relacionado somente à higiene, não colocando o homem em posição de autocuidado. Além disso, apesar dos estudos que buscam entender a relação do consumidor com os cosméticos e aqueles com enfoque nas características morfológicas e estruturais da pele masculina em detrimento da feminina, há poucos estudos focados no entendimento da cultura, consumo e como isso afeta, de fato na saúde da pele masculina. A grande maioria dos estudos de eficácia clínica ou sensorial de cosméticos são focados em 
público feminino com mais 30 anos. Na literatura há uma escassez para o entendimento do que seria um cosmético para público masculino, especialmente nas áreas de cuidados com a pele e como isso afetaria diretamente na saúde da pele desse segmento.

\subsection{O SENSORIAL E AS PROPRIEDADES FÍSICO-MECÂNICAS DE COSMÉTICOS}

O marketing parece distante da pesquisa e desenvolvimento de cosméticos, mas isso não é completamente correto. O sensorial, um apelo muito importante para a continuidade e fidelidade do uso de cosméticos, está atrelado à estrutura das formulações cosméticas, as chamadas propriedades físico-mecânicas. Dessa forma, marketing, análise sensorial e P\&D precisam caminhar juntos para o sucesso do investimento da formulação cosmética.

A pesquisa e desenvolvimento de cosméticos evoluiu muito nos últimos 30 anos, com o desenvolvimento de novas matérias primas, que melhoram a performance dos produtos cosméticos, bem como de metodologias para avaliação da formulação (INFANTE, MELO \& CAMPOS, 2018). O uso de polímeros em formulações cosméticas representou um avanço importante para o setor cosmético uma vez que foi possível aumentar a diversidade de formulações em relação às texturas, sensorial e até mesmo para a melhora da estabilidade (INFANTE, CALIXTO \& MAIA CAMPOS, 2019).

O avanço no estudo das propriedades sensoriais de produtos cosméticos foi importante para que fosse possível o desenvolvimento de produtos com propostas sensoriais mais alinhadas ao público masculino. Além disso, o uso de polímero possibilitou a redução da carga oleosa em formulações cosméticas, conseguindo contornar problemas relacionados à pele oleosa, característica ressaltada pelo público masculino como barreira para o uso de cosméticos (INFANTE, CALIXTO E MAIA CAMPOS, 2016). O sensorial de produtos cosméticos é importante para a adesão e uso constante das formulações, garantindo a eficácia do produto (CALIXTO et al, 2020).

As características físico-mecânicas das formulações cosméticas estão intimamente correlacionadas com a escolha das matérias-primas, suas concentrações, bem como com o processo empregado. O estudo dessas propriedades - como viscosidade, textura, consistência, entre outras - é importante porque serve de predição para características sensoriais, além de uma melhor compreensão das características relacionadas à estabilidade de cosméticos (CALIXTO \& MAIA CAMPOS, 2017). Dessa forma, podemos otimizar processos para a 
obtenção de produtos cosméticos mais estáveis e com melhor aceitação entre os consumidores (CALIXTO, INFANTE \& MAIA CAMPOS, 2018).

Ainda, a utilização de parâmetros de textura para a otimização de processos de formulação cosmética, bem como compreensão das propriedades de determinadas matériasprimas no sistema, tem sido descrita na literatura, podendo ou não ser acompanhada de desenho experimental estatístico (FOSSA SHIRATA, CAMPOS, 2017; SILVA et al., 2019; LEITE \& MAIA CAMPOS, 2019; FERREIRA et al., 2020). Podemos citar também estudos correlacionando o sensorial, a composição, a estabilidade e a eficácia de produtos cosméticos (WATSON et al., 2009; FOSSA \& MAIA CAMPOS, 2016; BOGDAN et al., 2017; LEITE \& MAIA CAMPOS, 2018).

Formulações semissólidas são caracterizadas por se deformarem quando um estresse lhe é aplicado. Esse estresse está intimamente relacionado às características físico mecânicas de formulações cosméticas (TAI, BAINCHINI \& JACHOWICZ, 2014). Além disso, a composição afetará diretamente tais propriedades (DUBUISSON et al., 2018). Ao espalharmos formulações cosméticas, elas tendem a se deformar na superfície da nossa pele e, dessa forma, a depender da composição e, consequentemente, da característica físico-mecânica, o sensorial percebido da formulação pode ser alterado, muitas vezes apenas modificando concentrações de matérias-primas (CALIXTO, INFANTE \& MAIA CAMPOS, 2018). Outro ponto a ser abordado é que, pensando em formulações fotoprotetoras, o estudo das características físicomecânicas pode estar correlacionado até mesmo com sua eficácia, não apenas na adesão devido ao sensorial, mas porque essas características afetam a forma como a formulação irá se comportar na superfície da pele e, consequentemente, sua eficácia (GASPAR \& CAMPOS, 2003; FERREIRA et al., 2020).

Gilbert et al. (2012) mostraram em seu estudo que diferentes polímeros em formulações cosméticas do tipo emulsão podem contribuir de diferentes formas nas características físicomecânicas. Polímeros de origem sintética costumam trazer firmeza ou consistência de forma mais efetiva aos cosméticos, enquanto as formulações com polímeros de origem natural como a hidroxietilcelulose não interferem tanto nesse aspecto. Isso foi observado em formulações apenas do tipo gel em estudo sobre textura de formulações poliméricas (INFANTE, CALIXTO \& MAIA CAMPOS, 2019). 


\subsection{POLÍMEROS SINTÉticos, NATURAIS E OS AMIDOS COMO MODIFICADORES REOLÓGICOS DE PRODUTOS COSMÉTICOS}

Se há correlação entre sensorial e características físico-mecânicas é preciso então estudar como substâncias modificadoras reológicas podem afetar - ou não - esses parâmetros.

Uma das questões sobre a utilização de polímeros sintéticos em formulações cosméticas está relacionada com os micros e nano plásticos que podem tornar-se potenciais poluentes. As partículas de plástico usadas nos cosméticos são muito pequenas (geralmente não maiores que cerca de um milímetro, mas podem ser tão pequenas quanto algumas dezenas de nanômetros): muitas são invisíveis a olho nu (BHATTACHARYA, 2016). Dentro dessas categorias de plástico, diferentes tipos de polímeros e copolímeros são aplicados em formulações cosméticas, como os acrilatos ou polietileno. As funções desses materiais nos produtos incluem formação de filme, regulação da viscosidade, condicionamento da pele, estabilização de emulsão e muitos outros, ou seja, estão correlacionados com a estabilidade e o sensorial de formulações cosméticas (LESLIE, 2014). Dessa forma, no desenvolvimento de produtos cosméticos com sensorial agradável ao público masculino e mais sustentáveis é necessária a utilização de polímeros alternativos aos utilizados pela indústria convencional.

Como mostrado anteriormente, muitos polímeros de origem natural não são bons modificadores das características físico-mecânicas e isso pode refletir diretamente na aceitação dos produtos pelos consumidores. Dessa forma, é preciso pesquisar e desenvolver alternativas mais sustentáveis, de menor custo e efetivas aos derivados de plástico que já são utilizados corriqueiramente. Uma alternativa é a utilização de amidos como espessantes e modificadores reológicos de formulações cosméticas, pois esses polissacarídeos são amplamente distribuídos, ocorrem na natureza e são econômicos (AGAMA-ACEVEDO \& BELLO-PEREZ, 2017). Tafuro et al. (2020) mostraram em seu estudo que polissacarídeos de origem natural dificilmente atingem as propriedades mecânicas de polímeros acrílicos como o carbômero, que apresentaram maiores valores, variando a concentração. Formulações com polímeros sintéticos costumam apresentar maior quantidade de ligações cross-link, estruturando melhor a formulação final, melhorando seu desempenho.

Amidos são biomoléculas - carboidratos - com capacidade polimérica encontrados como reservatórios de diferentes tipos de plantas. Geralmente estão localizados em tubérculos ou cereais, sendo compostos basicamente por amilose e amilopectina (AP). A quantidade desses dois polissacarídeos varia de acordo com a origem do amido em questão. A amilose é constituída de D-glicopiranose, ligadas por pontes glicosídicas $\alpha-1,4$, que conferem à molécula 
uma estrutura helicoidal e a AP caracteriza-se por ser menos hidrossolúvel do que a amilose, constituída por resíduos de $\alpha$-glicose ligadas por pontes glicosídicas $\alpha-1,4$, ocorrendo também ligações $\alpha-1,6$, que dão a ela uma estrutura ramificada (FRENCH, 1984; SHI \& SEIB, 1992).

Os grânulos de amido apresentam birrefringência quando observados sob luz polarizada, o que indica um certo grau de organização e sua adição em cosméticos é amplamente difundida (PASAPANE \& SOLAREK, 2001). A parte linear das moléculas de amilopectina forma estruturas helicoidais duplas, estabilizadas por pontes de hidrogênio entre grupamentos hidroxila. Alguns fenômenos afetam as propriedades dos amidos. Um deles é a gelatinização, o processo de transformação do amido granular em pasta viscoelástica e isso pode ser interessante do ponto de vista reológico para a aplicação em formulações cosméticas mais estáveis. Durante o aquecimento do amido em presença de água, inicialmente ocorre o inchamento de seus grânulos até temperaturas nas quais ocorre o rompimento deles, com destruição da ordem molecular e mudanças irreversíveis nas suas propriedades (SOUZA \& ANDRADE, 2000). A temperatura na qual ocorre este tipo de transformação é chamada de temperatura de gelatinização, sendo dependente da origem do amido (estando relacionada com as concentrações de amilose e AP) (SHI \& SEIB, 1992).

Por esse motivo, a utilização de amidos em cosméticos pode ser interessante, entretanto, essas biomoléculas podem ser necessárias em altas concentrações - acima de $20 \%$ - em formulações para a formação de redes poliméricas coesas o suficiente para a melhora da estabilidade de cosméticos (VIEIRA et al., 2020). Isso pode ser um problema para a estabilização, tendo em vista que a depender da fonte de amidos, problemas como coalescência podem ser observados. Ainda, segundo Vieira et al. (2020) a utilização de amidos como o de tapioca em formulações cosméticas podem ser associadas a percepção sensorial de frescor.

Dessa forma, uma das possibilidades de melhoria na estabilidade é a utilização de amidos modificados estruturalmente, com capacidade de melhorar as interações entre as cadeias cross-link por exemplo (LEHAMNN et al., 2008). Entretanto, há poucos relatos na literatura sobre a utilização de amidos de diferentes fontes vegetais e possíveis efeitos sinérgicos na textura e estabilidade de formulações cosméticas.

Por apresentarem a propriedade de formação de rede polimérica, os amidos podem se depositar na superfície da pele e, dessa forma, atuarem como agentes modificadores de sensorial (DE MELO \& MAIA CAMPOS, 2019; FAUCHEUX et al., 2020). Além disso, podemos utilizar polímeros em formulações cosméticas com a intenção de reduzir a quantidade de parte 
oleosa em formulações, indo de encontro com desenvolvimento de produtos cosméticos para o público masculino de pele oleosa (SHENG, 2008).

\subsection{A PELE OLEOSA, OS COMEDÕES E O ESTUDO DE EFICÁCIA DE PRODUTOS COSMÉTICOS NO PÚBLICO MASCULINO}

Uma das principais reclamações do público brasileiro - especialmente o masculino com relação à pele é a produção excessiva de sebo (INFANTE, CALIXTO, MAIA CAMPOS, 2016). Em situações de perfeito equilíbrio entre a produção e os requisitos de sebo, a pele apresenta boa aparência. É confortável, bem hidratada, limpa e fácil de decorar com cosméticos e não tão fácil de irritar. Em situações de déficit lipídico, a pele apresenta-se seca, áspera, sem brilho, eritematosa e escamosa, podendo ser acompanhada de quadros de coceira. Os produtos de maquiagem se espalham de maneira desigual e a irritação é comum. Em situações de excesso de conteúdo lipídico, a pessoa se sente desconfortável, com a pele oleosa, brilhante e pode atrapalhar no desempenho de produtos cosméticos. Sob essa condição, a pele pode ser afetada por acne, rosácea ou ambas. Em suma, o excesso de óleo é cosmético e dermatologicamente indesejável. Como resultado dos avanços no entendimento da fisiologia das glândulas sebáceas, da bioquímica e metabolismo lipídico epidérmico e da função dos lipídios da superfície da pele, estão sendo desenvolvidas estratégias para equilibrar as necessidades da pele com seus requisitos lipídicos ideais (ABRAMOVITS \& GONZALEZ-SERVA, 2001; de MELO, MAIA CAMPOS, 2018; LEITE, MAIA CAMPOS, 2020; MAIA CAMPOS et al., 2019).

Os lipídios secretados por essas glândulas têm várias funções, como manutenção da integridade da barreira lipídica cutânea, transporte de antioxidantes para a superfície da pele, atividade antimicrobiana e atividades pró e anti-inflamatórias, sendo responsáveis por retardar os processos de envelhecimento cutâneo. Ainda, estão relacionados com a geração de odor corporal e feromônios. Embora sua função seja importante, os casos de hiperseborréia causam grande desconforto e devem ser tratados (ZOUBOULIS et al., 2014; MAIA CAMPOS et al., 2019).

O funcionamento das glândulas sebáceas também está relacionado a alterações na fisiologia dos folículos, como por exemplo a hiperqueratinização que pode levar à formação de sinais clínicos típicos da pele oleosa, como poros dilatados e comedões. Esses comedões, se não tratados desde cedo, podem evoluir a lesões inflamatórias acneicas (pápulas, pústulas e cistos de acordo com o grau de acne). Por isso é importante o desenvolvimento de produtos cosméticos para a pele com tendência a acne pois agindo nos graus iniciais, as chances de 
formação de lesões inflamatórias são reduzidas (ZOUBOULIS, 2014; ZOUBOULIS et al., 2014; MAIA CAMPOS et al., 2019).

O comedão fechado é caracterizado por acúmulo de células mortas, sebo e proteínas que bloqueiam a abertura do folículo e aparecem como pequenas saliências esbranquiçadas abaixo da superfície da pele, enquanto um comedão aberto é uma lesão não inflamatória preenchida com excesso de óleo, proteína e células mortas da pele (MAIA CAMPOS et al., 2019). Essa oclusão é importante para a que a bactéria causadora da acne (C. acnes) encontre um ambiente propício para a sua proliferação, uma vez que apresenta metabolismo anaeróbico (DRÉNO et al., 2018).

Uma das principais alterações observadas com relação à pele masculina jovem é o surgimento de lesões que caracterizam a acne. Ela é caracterizada por um processo inflamatório crônico das glândulas sebáceas e dos folículos pilossebáceos. Por estar relacionada com o aumento de oleosidade e processo de hiperqueratinização - criando um ambiente propício para a proliferação de Cutibacterium acnes - o desenvolvimento de produtos cosméticos que auxiliem no controle da evolução é um importante fator para graus mais leves da doença. É importante ressaltar que os hormônios andrógenos como a testosterona estimulam a produção sebácea e para os homens isso é fator importante na evolução da fisiopatologia da acne (ZOUBOULIS, 2014; DRÉNO et al., 2018).

No entanto, embora a acne seja principalmente um distúrbio da adolescência, pesquisas atuais indicam que a prevalência de pacientes adultos com acne está aumentando (MCCARTY, 2016; KAMINSKY et al., 2019). De acordo com o tempo de início, são reconhecidos dois subtipos de acne adulta: persistente e tardia. A acne persistente é uma continuação ou recidiva da doença desde a adolescência até a idade adulta e meia-idade, enquanto o tipo de início tardio envolve pacientes com 25 anos ou mais de idade que não foram afetados anteriormente pela acne vulgar (SKROZA et al., 2016).

Como dito anteriormente, uma das características que levam ao desenvolvimento de uma lesão de acne é a hiperqueratinização da parede folicular. As células desta camada mostraram ter membranas celulares espessadas e sua integridade celular foi mantida com muitas camadas de células queratinizadas compactadas juntas. Isso era diferente da natureza dessas células encontradas nos folículos normais, que perdem sua integridade e são descartadas como grupos únicos ou menores de células. Esse processo dá origem ao tampão "córneo", formado dentro do ducto folicular, sendo um dos estágios iniciais da patofisiologia da acne (FARRAR \& INGHAM, 2004). Dessa forma, o desenvolvimento de produtos cosméticos que consigam 
atuar nesse estágio da acne, antes de desencadear o processo inflamatório, é uma forma de auxiliar para que reduzir o desenvolvimento de lesões inflamatórias - as chamadas pápulas e pústulas.

Há vários mecanismos importantes relacionados com o surgimento da acne: o primeiro deles é devido ao aumento de andrógenos circulantes, menos frequente, como observado em algumas síndromes. O segundo mecanismo, encontrado na acne vulgar, ocorre pela ação periférica do andrógeno. Na pele acnéica, há um aumento nessa produção do hormônio ativo, aumentando a secreção sebácea que pode ocasionar a oclusão dos folículos (ZOUBOULIS, 2004).

Bactérias do gênero Cutibacterium tem papel na patogênese da acne. Com a retenção sebácea, esse microrganismo anaeróbico se prolifera e hidrolisa os triglicerídeos, liberando ácidos graxos que são irritantes para a parede folicular e que induzem a queratinização. Tudo isso pode culminar em processo inflamatório no folículo (CHRISTENSEN et al., 2013; ZEEUWEN et al., 2013). Por isso é importante compreender o processo que envolve a formação da acne não-inflamatória, os comedões, auxiliando para a obtenção de dados que forneçam suporte para o desenvolvimento de produtos cosméticos, reduzindo a possível progressão para o estágio inflamatório.

O desbalanço lipídico também está relacionado com o surgimento da acne, por exemplo, quando há a falta de ácido linoleico na referido região há uma maior tendência a existir uma descamação celular, desta forma há uma perda da função barreira da pele. Com a perda desta função é importante ressaltar que a penetração de organismos e lipídios pró-inflamatórios acabam acarretando inflamação e infecção, o que pode resultar em casos de acne mais severos (DAS, 2014).

O metabolismo de carboidratos exerce determinado papel na hiperqueratinização folicular: a insulinemia influencia as concentrações de IGF-1 e IGFBP-3 (mediadores relacionados com a inflamação), regulando diretamente a proliferação de queratinócitos. A hiperinsulinemia eleva a IGF-1 livre e reduz a IGFBP-3, contribuindo para a hiperproliferação de queratinócitos no folículo (COSTA, 2008).

É importante ressaltar que a infecção por C. acnes também apresenta como via inflamatória a produção de IGF-1, por exemplo, desta forma, apesar das causas serem diferentes, elas acabam se complementando e, muitas vezes, uma influencia diretamente na outra. É o caso também da ingestão de determinados suplementos alimentares como Whey 
Protein (muito utilizado pelo público masculino). A ingestão destes suplementos está também relacionada com o aumento de IGF-1, estimulando a lipogênese de glândulas sebáceas, bem como a inflamação folicular e a estimulação androgênica (MCCARTY, 2016).

Os tratamentos atuais compreendem uma variedade de medicamentos tópicos e sistêmicos, com o objetivo de diminuir a produção de sebo, inibir o crescimento bacteriano, reduzir a inflamação e/ou normalizar a queratinização nos folículos. Os tratamentos orais atuais são geralmente bem-sucedidos; no entanto, seus efeitos colaterais geralmente resultam em desconforto do paciente e, no caso da isotretinoína, podem envolver até dano hepático (SCHEINFELD, 2007). Dessa forma, a utilização ou não desse tipo de terapia deve ser bem pensada pelos profissionais médicos, sendo que para quadros mais leves outras terapias devem ser aplicadas (VALLERAND et al., 2018). Outra forma de tratamento consiste na utilização de antimicrobianos tópicos, geralmente o tratamento preferido e exercem um efeito supressor nos patógenos bacterianos envolvidos na acne; no entanto, eles são limitados em seu uso devido ao desenvolvimento de resistência (WALSH, EFTHIMIOU \& DRÉNO, 2016). Isso enfatiza a importância de descobrir tratamentos alternativos para a acne, especialmente em sua fase não inflamatória que pode ser contemplado pela utilização de cosméticos, mantendo a homeostase cutânea e reduzindo a formação de acne não inflamatória e posterior evolução do quadro clínico (ORCHARD et al., 2018). Os cosméticos não são os principais agentes no tratamento da acne, mesmo não inflamatória, mas podem ser importantes coadjuvantes e pesquisas precisam ser conduzidas nesse campo dermatológico.

Apesar da importância mercadológica acerca do público masculino e o consumo de cosméticos, na literatura há poucos estudos que se preocupam em entender como agem determinados cosméticos em populações masculinas. A grande maioria desses trabalhos está relacionada à alopecia androgenética, que acaba se valendo de medicamentos para o seu tratamento (SISTO, BUSSOLETTI \& CELLENO, 2013; ZHU et al., 2020).

\subsection{A UTILIZAÇÃO DE ÓLEOS ESSENCIAIS EM PRODUTOS COSMÉTICOS E SUA SEGURANÇA E EFICÁCIA}

A utilização de terapias alternativas como, por exemplo, óleos essenciais têm ganhado destaque dentro da dermatologia, especialmente com o que diz respeito à acne. Entretanto há ainda pouca evidência sobre a ação desses compostos na pele, sobre sua eficácia, possível perturbação dos lipídeos da barreira cutânea e especialmente com relação ao desenvolvimento de produtos cosméticos seguros e eficazes. 
O termo "óleos essenciais" refere-se a extratos voláteis de plantas com aromas distintos (ou seja, a chamada "essência" da planta). Os óleos essenciais podem ser usados de várias maneiras, como misturado em gel, composto em uma pasta ou spray, ou aplicado via banho, massagem ou inalação (LERTSATITTHANAKORN et al., 2006). Entretanto, em produtos para o uso prolongado na pele há pouca evidência clínica de sua eficácia e principalmente com relação à sua segurança.

Na literatura, o termo "óleo essencial" pode ser encontrado incorretamente em muitos produtos extraídos de produtos de origem vegetal por métodos diferentes da destilação ou prensagem a frio. Absolutos, águas aromáticas e concentrados são produtos que são produzidos a partir de material vegetal, mas não são óleos essenciais. Esses produtos são usados como parte de um produto cosmético ou como produto cosmético per se, como águas aromáticas. Águas aromáticas, também conhecidas como hidrolatos, são soluções aquosas dos óleos essenciais que permanecem após a destilação a vapor do material vegetal (por exemplo, "água de rosas") (SARKIC \& STAPPEN, 2018).

Podemos extrair óleos essenciais através de destilação a vapor e o método mais famoso para flores é o enfleurage. A destilação a vapor é considerada não adequada para produtos obtidos de algumas flores pois contêm compostos sensíveis à alta temperatura. Absolutos são produtos obtidos principalmente a partir de concretos, resinóides, extratos de fluidos supercríticos ou pomadas usando etanol como solvente através da enfleurage. Esses produtos não contêm apenas fragrâncias voláteis, mas todos os componentes lipofílicos e alguns compostos lipídicos. Absolutos são mais utilizados na indústria de fragrâncias e perfumes, uma vez que os compostos lipídicos podem auxiliar para a fixação do perfume na pele (STICHER, HEILMANN \& ZÜNDORF, 2015). Todo óleo essencial possui em sua composição diferentes terpenos e essas moléculas são marcados importantes para o controle de qualidade do produto.

Óleos essenciais apresentam algumas substâncias que, sabidamente, podem ser irritantes como o linalol. Das 26 substâncias com potencial alergênico estabelecidas pela União Européia, 18 são encontradas em óleos essenciais (SARKIC \& STAPPEN, 2018). Entretanto a literatura carece de estudos mais aprofundados sobre penetração e ação dessas substâncias ativas na barreira da pele, bem como compatibilidade cutânea.

O óleo essencial de lavanda é um líquido límpido, incolor a amarelo pálido com um odor característico que é extraído por destilação a vapor dos topos floridos do Lavandula angustifolia Mill. De acordo com a norma ISO, o óleo deve conter acetato de linalil (25-47\%), linalol (máx. 45\%), terpinen-4-ol (máx. 8\%), cânfora (máx. 1,5\%), limoneno (máx. 1\%) e 1,8- 
cineol (máx. 3\%) (ISSO 3515). É conhecido por possuir atividade antioxidante, antifúngica e antibacteriana. $\mathrm{Na}$ aromaterapia é utilizado para reduzir sintomas de estresse, estando relacionado com bem-estar (CAVANAGH \& WILKINSON, 2005). Kazemi et al. (2020) mostraram em seu estudo que uma nanoemulsão combinando óleo essencial de lavanda e licorice apresentou uma melhora na cicatrização de queimaduras em ratos. Cardia e colaboradores (2018) apresentaram em seu estudo que a utilização de óleo essencial de lavanda pode reduzir a resposta inflamatória aguda da pele. BIAŁOŃ et al. (2019) mostraram em seu estudo que a utilização de óleo essencial de lavanda pode ser interessante para o controle da microbiota da pele.

Outro óleo essencial muito estudado é o de Eucalyptus globulus. Esse óleo essencial apresenta cerca de 70\% (v/v) de eucaliptol. Ele apresenta atividade anti-inflamatória, antiviral, antibacteriana, antioxidante e antifúngica bem descritas na literatura (DHAKAD et al., 2018). Por possuir alta atividade antioxidante e auxiliar na recuperação de queimaduras, Stafa et al. (2018) propuseram a utilização de óleo essencial de eucalipto para combater os danos causados por agressões ambientais como poluição. Park et al. (2018) mostraram em seu estudo que a utilização de óleo essencial de eucalipto pode auxiliar para reduzir os danos causados pelo fotoenvelhecimento da pele, estimulando a produção de colágeno em testes in vitro, além de reduzir a inflamação aguda causada pelo UVB.

O óleo essencial de tangerina (Citrus reticulata) é rico em limoneno e apresenta alta atividade antioxidante, antibacteriana e antifúngica (MANDAL \& MANDAL, 2016). Não é muito utilizado em produtos cosméticos de uso tópico, porém há estudos que mostram que a utilização de formulações com esse óleo essencial pode apresentar uma boa atividade nos parâmetros de hidratação da pele (KHAM, ALI \& ALAM, 2010). Kwangjai et al. (2020) mostraram em seu estudo que esse óleo essencial apresenta uma relação com efeito hipnóticos, também podendo ser um interessante ingrediente para a indústria cosmética utilizar pensando no bem-estar.

Interessante ressaltar que há estudos e revisões na literatura focando no tratamento da acne inflamatória utilizando óleos essenciais e em destaque ao de Melaleuca alternifolia, com principal componente sendo o terpinen-4-ol, mas há quase nenhum relato de sua atividade na barreira hidrolipídica da pele, algo muito importante para a pele acneica (DECKER \& GRABER, 2012; CHULAROJANAMONTRI et al., 2014; HAMMER, 2015). Além disso, a maioria dos estudos vale-se de concentrações de 5\% de óleo essencial de melaleuca, uma quantidade alta que pode não ser bem tolerada pela pele (HAMMER, 2015). Kim \& Chin (2013) 
mostraram em seu estudo que quando aplicados juntos, os óleos essenciais de lavanda e melaleuca, duas vezes por dia e depois lavados houve uma redução no número de lesões inflamatórias após 4 semanas. Entretanto, mais uma vez, não vemos discussões acerca da função barreira da pele, essencial para a manutenção das características da pele.

Óleos essenciais são potencialmente irritantes, porém também podem apresentar uma função interessante para auxiliar na penetração de substâncias ativas através da pele, melhorando assim a eficácia da terapia (HERMAN \& HERMAN, 2015). Southwell, Freeman e Rubel (1997) demonstraram em seu estudo que o óleo essencial de melaleuca não é irritante, mesmo em altas doses, mas dos 25 participantes, 3 apresentaram uma reação alérgica a determinados componentes (não majoritários) do óleo essencial.

Deyno et al. (2019) mostraram em sua revisão sistemática e meta-análise que óleos essenciais podem ser alternativas para o tratamento da acne em quadros mais brandos. Em outro estudo, $0.74 \%(\mathrm{~m} / \mathrm{m})$ de óleos essencial de Origanum vulgare, $3.15 \%(\mathrm{~m} / \mathrm{m})$ de óleo essencial de Myrtus communis L. e $0.025 \%(\mathrm{~m} / \mathrm{m})$ de tretinoína em uma composição cosmética apresentou resultado satisfatório na diminuição de lesões inflamatórios e nos efeitos adversos da tretinoína na pele (MAZZARELLO et al, 2020). Enshaieh et al. (2007) apresentaram em seu trabalho duplo cego e placebo-controle que a utilização de óleo essencial de $M$. alternifolia a 5\% em acne leve a moderada foi até cinco vezes melhor na redução dos sinais clínicos.

Com relação a estudos focados no desenvolvimento de produtos cosméticos com óleos essenciais, há pouca literatura que mostre o impacto desses componentes em parâmetros de textura e reologia, por exemplo (JOSHI \& PAWAR, 2017). A maioria desses estudos visam aumentar a estabilidade do óleo essencial, reduzindo sua volatilidade, através do desenvolvimento de nanoemulsões e nanopartículas (BILIA et al., 2014).

Dentre todos os óleos essenciais utilizados, para a acne ganha-se destaque o de Melaleuca alternifolia, porém outros tem ganhado espaço como, por exemplo, o de orégano (TALEB et al., 2018). A utilização de óleos essenciais, apesar de ser uma prática popular, carece de evidência e vários estudos precisam ser feitos, especialmente levando em consideração modelos ex vivo e in vivo. Isso é importante porque o conhecimento de como os óleos essenciais perturbam - ou não - a barreira da pele, além do entendimento do perfil de penetração desses óleos ainda é limitado. Entretanto, esses estudos podem ser cruciais para entendermos as limitações e aplicações de modelos in vitro. Por exemplo, se um óleo é considerado citotóxico em cultura celular - modelo in vitro - através de estudos com modelos ex vivo - orelha de 
porco, por exemplo - podemos entender se há a penetração através do estrato córneo que, de fato, possa afetar os queratinócitos.

Os óloes essenciais podem apresentar problemas de estabilidade causados pelo contato direto da atmosfera com os terpenos. Além disso, os terpenos podem ser voláteis e, em formulações cosméticas, podem evaporar, reduzindo a ação do referido cosmético. A utilização de sistemas de liberação controlada como nanoemulsões pode ser uma forma inteligente de aumentar a estabilidade desses componentes e melhorar a veiculação dos óleos essenciais, bem como a penetração através do estrato córneo (PAVONI et al. 2020).

\subsection{METODOLOGIAS IN VITRO, EX VIVO E IN VIVO E O ESTUDO DE SUBSTÂNCIAS ATIVAS UTILIZADAS EM COSMÉTICOS}

Podemos utilizar diferentes metodologias para o estudo da segurança e eficácia de cosméticos. Cada uma delas apresenta suas vantagens e limitações e precisam ser selecionadas de acordo com a necessidade dos objetivos propostos. Podemos encontrar métodos in vitro, ex vivo e in vivo.

Um ensaio in vitro é um ensaio fora de um organismo vivo e envolve normalmente células, tecidos ou órgãos isolados. Por exemplo, podemos utilizar diferentes modelos de queratinócitos para testes de segurança de cosméticos. Nesse caso estamos testando a substância diretamente na célula. Podemos utilizar dados obtidos a partir de ensaios in vitro para cumprir, total ou parcialmente, requisitos de informação que, de outra forma, necessitariam de dados obtidos a partir de ensaios em organismos vivos (ensaios in vivo). Outro tipo de ensaio in vitro é utilizando pele reconstituída, uma vez que houve a extração de queratinócitos para a reconstrução do epitélio em laboratório (TAVARES et al., 2020). A complexidade do sistema de avaliação não tem necessariamente relação com o fato de ser in vitro, ex vivo ou in vitro.

É importante também a utilização de estudos in vitro para a identificação de possíveis agentes cito e/ou fototóxicos, dependentes ou não da concentração (CANNAS et al., 2016). Esse assunto é mais explorado e tem muitas aplicações importantes como, por exemplo, a busca por novas moléculas capazes de atuarem em diferentes tipos de câncer (OLIVEIRA et al, 2015). Para produtos cosméticos torna-se importante tal pesquisa na busca de produtos que sejam seguros e eficazes. Para óleos essenciais a fototoxicidade é importante porque muitos desses compostos apresentam certa atividade ao entrarem em contato com a luz solar, como o óleo de bergamota. Essas informações podem ser cruciais no momento de informar ao consumidor 
como e quando utilizar o produto cosmético (KEJLOVÁ, 2007; KEJLOVÁ, 2010; BINDER et al., 2016).

Métodos ex vivo são aqueles que se utilizam de partes de tecidos para a avaliação de substâncias e que apresentam certa similaridade com o modelo humano. Para isso é necessário que o modelo em questão tenha sido validado e mostrado validação com o sistema ao qual representa com relação ao humano. Na dermatologia, por exemplo, utilizam-se parte de pele oriundas de cirurgia ou o modelo de orelha de porco que apresenta grande similaridade com a pele humana na questão de organização da barreira cutânea, por exemplo (HAAG et al., 2010; ARNDT et al., 2013).

Com relação ao estudo in vivo, estamos falando diretamente do estudo em humanos ou animais em determinados casos e a observação dos seus efeitos da substância aplicada. Para o estudo com produtos cosméticos não é mais permitido o uso de animais no Brasil, Europa e Estados Unidos (VINARDELL \& MITJANS, 2017).

\subsection{O FOTOENVELHECIMENTO CUTÂNEO E A UTILIZAÇÃO DE PROTETOR SOLAR ENTRE HOMENS}

É inegável a importância da radiação solar para a nossa pele em uma exposição controlada. As radiações provenientes do Sol são responsáveis por interagir com os cromóforos presentes em nossa pele e catalisar reações importantes para a biologia cutânea e até mesmo a nível sistêmico como é o caso da vitamina D. Entretanto, essa exposição não pode ser prolongada de forma desprotegida, o que pode causar um desbalanço no estresse oxidativo cutâneo, tornando os efeitos deletérios mais proeminentes do que os efeitos benéficos (DE ASSIS et al. 2021). A exposição prolongada, especialmente desprotegida, pode levar ao câncer de pele e processo de fotoenvelhecimento (KRUTMAN et al. 2017). Isso é dependente de condições sócioculturais como acesso a proteção solar, normas masculinas e de fatores geográficos (McKENZIE et al. 2019; INFANTE et al. 2021).

O fotoenvelhecimento é caracterizado por um processo de envelhecimento diferente do que é observado no intrínseco (MERCURIO et al., 2016). A pele normalmente envelhecida que não foi exposta cronicamente à luz solar é caracterizada por rugas generalizadas, aparência seca e fina e queratoses seborreicas, com redução nos parâmetros viscoelásticos da pele. A pele fotoenvelhecida também, mas em um grau mais elevado e a aparência das rugas geralmente é um pouco diferente. Há também questões relacionadas com a presença de telangiectasias e distúrbios no padrão de pigmentação como agravamento do melasma (FLAMENT et al., 2013). 
No entanto, as alterações induzidas pela exposição crônica ao sol podem ocorrer bem antes dos sinais clínicos de envelhecimento da pele, causando alterações na morfologia da pele que ainda não são perceptíveis ao olhar clínico (SHIRATA et al., 2019). Há uma grande variação interindividual com relação às características clínicas da pele fotoenvelhecida, dependendo principalmente de fatores como tipo de pele, natureza da exposição ao sol, penteado, vestuário, condições socioeconômicas, cultura e hábitos (BERNEBURG et al., 2000).

Outro aspecto que ocorre na pele fotoenvelhecida é a hiperqueratose do estrato córneo, uma forma de tentar reduzir os danos causados pela exposição solar desprotegida. A epiderme pode ser hipertrófica, atrófica ou inalterada (BERNEBURG et al., 2000). A espessura da membrana basal é aumentada, possivelmente refletindo os danos aos queratinócitos basais e a distribuição dos melanócitos ao longo da membrana basal é irregular e essas células variam em tamanho, dendricidade e pigmentação (BREATHNACH \& WYLLIE, 1964; MERCURIO et al., 2016). Na derme, há um gradiente de dano progressivo da exposição aos raios UV, especialmente com o que diz respeito às fibras de colágeno, não sendo um processo totalmente homogêneo. Podemos observar também a presença de elastose solar, especialmente na região da derme papilar. Há também a deposição de fibras de elastina e glicosaminoglicano degradas, o que reduz os parâmetros de viscoelasticidade da pele (BERNEBURG et al., 2000).

Basicamente o que podemos observar é que o dano cutâneo causado pela exposição solar desprotegida e de forma crônica não é um processo homogêneo, dependendo de fatores individuais e especialmente com relação aos hábitos, cultura e sazonalidade. $\mathrm{O}$ estudo das características morfológicas e estruturais da pele fotoenvelhecida ganhou maior destaque na última década com a utilização de técnicas de microscopia não invasiva para a avaliação das alterações causada pela exposição desprotegida.

Longo et al. (2013) utilizou em seu trabalho uma metodologia não invasiva para a avaliação do processo de fotoenvelhecimento da pele: a microscopia confocal de reflectância a laser. É possível, com a utilização desse aparelho, acessar o estrato córneo, a epiderme e a derme papilar - mais superior - sem a necessidade de cortes para biópsia, por exemplo. Esse trabalho é o guia principal para entendermos, através dessa microscopia, como avaliar o fotoenvelhecimento.

O trabalho contou com 75 participantes, divididos em 5 grupos de acordo com a idade - variando entre jovens com menos de 35 anos até pessoas com mais de 65 anos. É importante ressaltar que aqui foram avaliados homens e mulheres, sem recortes de sexo biológico. Os autores queriam saber sobre como avaliar o fotoenvelhecimento utilizando a microscopia 
confocal de reflectância comparando com biópsia de 4 participantes. Todos os voluntários foram avaliados por dermatologistas para a obtenção do score de fotoenvelhecimento visível e os resultados foram comparados com as imagens obtidas pelo confocal. Foram avaliados 8 parâmetros na microscopia confocal:

- $\quad$ Estrato córneo: espessura e aparência romboidal

- $\quad$ Epiderme viável: espessura, padrão de organização celular como favo-de-mel e a pigmentação mosqueada (basal)

- Derme superior e junção derme-epiderme: glândulas sebáceas, as papilas e suas qualidades e a arquitetura da matriz derma-papilar.

Um dos achados mais interessantes está relacionado com a rede de colágeno que tende a diminuir o brilho conforme o dano solar, mas quando chega na situação de elastose, há um aumento progressivo desse brilho, porém com diferente organização estrutural e morfológica. Nesse trabalho foi possível observar correlações com o estudo de biópsia e, dessa forma a metodologia pode ser aplicada para outros estudos.

Shirata et al. (2019) mostraram em seu estudo que os sinais de fotoenvelhecimento da pele facial de mulheres jovens estão mais relacionados à presença de hiperpigmentações cutâneas, alterações no formato das papilas na JDE e alterações na estrutura do colágeno. Além disso, as alterações observadas para a o público feminino de pele madura são basicamente as mesmas, porém mais acentuadas.

Wurm et al. (2012) apresentaram em seu estudo com homens e mulheres que a utilização do confocal foi interessante para revelar o padrão arquitetural e as características morfológicas da pele devido ao envelhecimento cronológico e exposição cumulativa aos raios UV. Nesse estudo comparou-se os sítios de exposição solar, ou seja, o antebraço dorsal, com sítios de menor exposição como a parte interna do antebraço. Foi observado que as partes mais expostas apresentavam níveis mais altos de desorganização das papilas localizadas na junção dermeepiderme.

A grande maioria dos estudos que buscam entender o fotoenvelhecimento utiliza o público masculino em sua casuísta, entretanto, os estudos não se importam em entender a fundo as influências dos hábitos de fotoproteção dessa população. Além disso, há nenhuma literatura que mostre a relação da influência cultural nos hábitos de fotoproteção e consequente influência na saúde e qualidade da pele. Muitos dos estudos com essa finalidade - ou parecida - focam 
principalmente no público feminino (MARTINI et al., 2017; MARTINI \& MAIA CAMPOS, 2018; SHIRATA et al., 2019).

A revisão apresentada até aqui já enfatizou que há uma resistência do público masculino em utilizar produtos cosméticos e isso reflete nos hábitos de fotoproteção. Há também poucos estudos que correlacionem os hábitos com os impactos na saúde da pele do homem, bem como a importância da apresentação do homem na mídia utilizando cosméticos e especialmente a fotoproteção.

\subsection{A PESQUISA E DESENVOLVIMENTO DE FOTOPROTETORES}

A pesquisa e desenvolvimento de formulações fotoprotetoras é um ramo que vem se desenvolvendo continuamente desde os anos 90. De formulações com baixo fator de proteção solar, com apenas proteção UVB e sensorial pesado, passamos para formulações com diferentes sensoriais, com diferentes propostas, com proteções que englobam todo o espectro da radiação UV, luz visível e até mesmo infravermelho (ZASTROW et al., 2017).

A proteção UVB está relacionada com o fator de proteção solar (FPS) e a proteção UVA com o PPD (Persistent Permanent Darkening) que precisa sempre ser, ao menos, 1/3 do valor obtido para o UVB. Todos os testes são realizados com quantidade padronizada de produto $\left(2 \mathrm{mg} / \mathrm{cm}^{2}\right)$. Esses valores estão relacionados com a concentração e tipo de filtros UV que são selecionados para a formulação. Além disso, fotoprotetores precisam proteger, pelo menos, 90\% do espectro UV (ZATROW et al., 2017).

Toda formulação fotoprotetora apresenta em sua composição filtros UV que são os responsáveis pela proteção dos rádios UV oriundos do Sol. Esses filtros podem ser classificados como orgânicos ou inorgânicos. Os filtros orgânicos são em maior número e são moléculas com capacidade de absorver e estabilizar os fótons oriundos da radiação solar. Cada um desses filtros apresentam uma faixa de absorção no UV, sendo necessária muitas vezes a utilização de mais de um deles em uma formulação para proteger todo o espectro UV (SERPONI et al., 2007).

Compostos minerais como dióxido de titânio e óxido de zinco são usados em cosméticos como bases, pós, sombras para os olhos e lápis e são os conhecidos filtros inorgânicos. De fato, o dióxido de titânio (TiO2) é retratado como filtro solar desde 1952 (SMITHERS \& WOOD, 1952). Os filtros inorgânicos atuam por meio de absorção, espalhamento e reflexão da luz solar. Essas propriedades dependem do índice de refração, tamanho das partículas, dispersão na base de emulsão e espessura do filme formado (SERPONI et al., 2007). Os filtros inorgânicos podem também atuar na proteção da luz visível, entretanto, o tamanho de partícula precisa ser grande 
o suficiente para atuar como pigmento, o que causa desconforto para quem utiliza o fotoprotetor, por conta do resíduo branco. Os fotoprotetores mais modernos que constam com esse tipo de filtro solar reduzem muito o tamanho da partícula, melhorando o desconforto com relação ao sensorial, mas comprometendo a proteção da luz visível (BOUKARI et al., 2015).

Lademann et al. (2006) mostraram em seu estudo que as partículas muito pequenas de filtros inorgânicos podem ser estocadas em folículos em períodos de até uma semana. Essa informação é importante porque se a pele mantém as partículas estocadas, o real valor de fotoproteção pode ser diferente, porém o mais importante está relacionado com processos que possam causar alergia devido à exposição prolongada. Dessa forma, é preciso entender que fotoprotetores híbridos - associando filtros químicos e físicos - podem ser uma boa opção para reduzir também esse problema.

Podemos associar filtros orgânicos e inorgânicos por conta de sua ação sinérgica (LADEMANN et al., 2005). Os filtros particulados podem aumentar o scattering, desviando a luz e aumentando o caminho que o fóton fará. Dessa forma, as chances de ele ser absorvido pelos filtros químicos e/ou serem refletidos por ação secundária pode ser aumentada (MEINKE et al., 2011).

Idealmente esses filtros devem ficar na superfície da pele e não penetrarem mais do que o estrato córneo. WEIGMANN (2005) mostrou em seu trabalho que através de técnicas de tape stripping é possível analisar a penetração de filtros UV no estrato córneo e que para uma formulação bem elaborada de fotoprotetores eles não penetram mais do que $30 \%$ o estrato córneo - correspondente aos sulcos observados na superfície do estrato córneo.

A proteção solar, como mostrado acima, está relacionado com a concentração de filtros UV de um fotoprotetor, porém não apenas com isso. Ação sinérgica entre filtros, propriedades ópticas, melhora na formulação cosmética e a utilização de moléculas capazes de estabilizar filtros solares e/ou auxiliarem na fotoproteção são formas inteligentes de melhorar a eficácia das formulações fotoprotetoras (HUNTER \& TREVINO, 2004). Ainda, podemos utilizar nanopartículas que auxiliam na estabilização dos filtros (NIKOLIC et al., 2011).

Não existe na literatura um estudo que enfoque no desenvolvimento de fotoprotetores para o público masculino. Isso porque a radiação solar irá afetar a pele independente do sexo biológico. O desenvolvimento de um fotoprotetor para o público masculino é um desdobramento do marketing. Entretanto, no desenvolvimento de formulações fotoprotetoras 
podemos levar em consideração aspectos com relação aos comportamentos observados por esse grupo e como isso afeta na saúde da pele e aplicar ao desenvolvimento.

\subsection{A ATIVIDADE ANTIOXIDANTE, AS PROPRIEDADES ÓPTICAS DE FOTOPROTETORES E A PROTEÇÃO DA LUZ VISÍVEL E INFRAVERMELHO}

A proteção da luz visível utilizando fotoprotetores e/ou produtos cosméticos com óxido de ferro - ou seja, com cor - já é bem estabelecida na literatura e pode auxiliar para a redução de hiperpigmentação ou agravamento do melasma (MARTINI \& MAIA CAMPOS, 2018).

Entretanto, a utilização de produtos com cor pode ser um inconveniente para muitos consumidores, especialmente quando falamos do público masculino que já enfrenta problemas para a utilização dos fotoprotetores convencionais. Dessa forma, o desenvolvimento de fotoprotetores que apresentem capacidade antioxidante pode ser uma forma de proteger a pele em um espectro que abrange também a luz visível e a infravermelho.

Associar antioxidantes às formulações fotoprotetoras é uma prática antiga, porém nos últimos dez anos têm ganho especial atenção por conta das evidências para a proteção contra radiação visível e infravermelho.

Mann et al. (2020) demonstrou em seu estudo que a utilização de molécula antioxidante em fotoprotetores reduziu a produção de radicais livres pela pele quando irradiada em diferentes comprimentos de onda. Souza e colaboradores (2017) observou o mesmo parâmetro.

É importante também estudar as propriedades ópticas dos fotoprotetores pois como observado no trabalho de Meinke et al. (2011), apesar de possuírem fatores de proteção de radicais livres, formulações que apresentavam melhores scaterrings acabavam por reduzir mais o estresse oxidativo a que a pele era exposta.

\subsection{O PERFIL DE PERMEAÇÃO DE SUBSTÂNCIAS ATIVAS USANDO TAPE STRIPPING E ESPECTROSCOPIA RAMAN ACOPLADA A MICROSCOPIA CONFOCAL DE REFLECTÂNCIA A LASER}

Há várias metodologias para a compreensão do perfil de permeação de substâncias no estrato córneo como por exemplo, tape stripping que consiste na retirada de camadas do estrato córneo utilizando-se fita adesiva. É possível retirar várias fitas para um mesmo local e observar o quanto determinada substância penetrou. Essa medida pode ser feita diretamente com espectofotômetro adequado ou extraindo o conteúdo da fita (WEIGAMANN et al., 2005). Para a compreensão de penetração de filtros UV podemos utilizar essa metodologia e em casos 
duvidosos podemos associar a metodologias mais robustas como a microscopia RAMAN (WEIGAMANN et al., 2005; SOUZA et al., 2017).

Entretanto, para substâncias voláteis como óleos essenciais podem encontrar alguns problemas metodológicos para sua realização (ESCOBAR-CHAVEZ, 2008). Podemos utilizar outras metodologias mais modernas e menos invasivas, como a espectroscopia Raman acoplada a microscopia confocal de reflectância a laser (CHOE, LADEMANN \& DARVIN, 2015a). Essa metodologia já descreveu a utilização de óleos minerais e vegetais para o uso na pele, além de ser possível utilizá-la para analisar a presença de substâncias ativas em diferentes camadas do estrato córneo e se chegam até a epiderme viável (CHOE, LADEMANN \& DARVIN, 2014; CHOE, LADEMANN \& DARVIN, 2015a; CHOE, LADEMANN \& DARVIN, 2015b; ESSENDOUBI et al., 2016).

É possível também observar como substâncias podem - ou não - interagir com os lipídeos da barreira da pele, sendo uma metodologia mais acurada e com mais informações do que apenas o perfil de permeação de substâncias ativas. Para estudar os parâmetros fisiológicos dependentes da profundidade do estrato córneo, a microscopia Raman confocal pode ser usada como uma poderosa ferramenta não invasiva oferecendo a capacidade de medir a ordem conformacional do estrato córneo, ordem de empacotamento lateral e transições de estado lipídico (CHOE et al., 2017).

A utilização dessa metodologia para o estudo do comportamento de óleos essenciais na pele ainda é limitada e precisa ser mais explorada, sendo principalmente utilizada para a determinação de adulterações de óleos essenciais através de mudanças observadas nos perfis da espectroscopia (WILLIAMS et al., 2006; FARAG et al., 2018). 
10. CONCLUSÃO 
Os principais produtos utilizados pelos homens são relativos à higiene e perfumaria. Médicos são um canal de comunicação entre os homens brasileiros e produtos cosméticos. O homem raramente é representado na mídia em contato com cosméticos, mesmo fotoprotetores. Os homens querem consumir cosméticos, porém ainda encontram uma barreira que associa seu uso a público feminino e negação do processo de autocuidado.

De acordo com os resultados obtidos no estudo de caracterização da pele, observamos que os garotos sem hábito de fotoproteção apresentaram piores características morfológicas, estruturais e hidrolipídicas em todas as avaliações realizadas com as técnicas de biofísica e imagem da pele. Mesmo jovens há evidências de sinais clínicos de fotoenvelhecimento em estado mais avançado do que aqueles com hábitos regulares de fotoproteção. Essas alterações estão relacionadas com um processo inflamatório agudo com presença de eritema e edema. A utilização de protetor solar durante 15 dias já reduziu consideravelmente essas observações.

Homens mais velhos que não usam fotoprotetor apresentam danos mais cumulativos em camadas mais profundas do que homens mais jovens, que apresentam uma extensão de danos mais heterogênea que podem variar com vários fatores, entre eles, os hábitos de exposição solar. Homens mais velhos apontaram também enfrentar uma barreira de uso dos produtos cosméticos, o que impacta diretamente na saúde da pele.

Além disso, o desenvolvimento de produtos cosméticos para o público masculino precisa ser pensado além das diferenças fisiológicas em relação às mulheres, sendo importante pensar a própria relação dos homens com cosméticos e sua representação nas publicidades.

Na etapa de desenvolvimento das formulações observamos que a utilização de amidos em sinergia pode ser uma alternativa ao uso de polímeros de origem sintética, reduzindo possíveis impactos ambientais. Essa tecnologia foi empregada em todo o desenvolvimento, auxiliando nas formulações fotoprotetoras e com óleos essenciais. A adição de PEG-75 lanolina no fotoprotetor melhorou as características físico-mecânicas da formulação, melhorando a dispersão dos filtros na superfície da pele e melhorando o FPS da formulação, sem adicionar mais filtros UV. Também observamos o aumento do FPRL e do índice de dispersão para a luz visível, mostrando que a formulação apresenta uma eficácia superior e pode ser uma alternativa aos homens jovens que não tem hábitos cosméticos.

Os óleos essenciais apresentaram perfil de segurança satisfatório, apenas o óleo de tangerina apresenta citotoxicidade dependente de concentração e esse mesmo óleo é o que apresenta o maior perfil de penetração. Os demais óleos essenciais têm a tendência de ficarem 
mais retidos no estrato córneo, especialmente os de lavanda e melaleuca. Todos os óleos essenciais foram não fototóxicos. O óleo de melaleuca apresentou um FPRL muito alto, sendo interessante para a utilização em cosméticos com aplicações contra o fotoenvelhecimento, muito recorrente entre os rapazes jovens.

Com relação à acne não inflamatória, o aumento da queratinização folicular pode ser reflexo da exposição solar desprotegida, o que leva também a um maior comprometimento da região folicular, que pode levar a lesões inflamatórias. A utilização de técnicas de biofísica e imagem da pele, bem como o estudo detalhado com relação às alterações morfológicas da região folicular, foram fundamentais para a implentação de protocolo clínico adequado para avaliação dessas lesões não inflamatórias.

No estudo clínico observamos que as formulações 4OE, melaleuca e nanoemulsão apresentaram os melhores resultados. A formulação 4OE apresentou melhoras nas propriedades hidrolipídicas da pele, refletindo em melhor estruturação das camadas superiores da epiderme. Não foi observado o mesmo com os $3 \mathrm{OE}$, mostrando uma atividade sinérgica do óleo de melaleuca com os demais. Isso foi observado na penetração, provavelmente porque a melaleuca diminuiu a penetração dos óleos e eles ficaram mais depositados nas camadas superiores, o que refletiu nas melhoras observadas.

A nanoemulsão e óleo essencial de melaleuca não encapsulado atuaram de forma mais expressiva nas camadas mais profundas da pele, melhorando a morfologia e densidade das papilas dérmicas e colágeno, especialmente no grupo que aplicou o óleo essencial de melaleuca, o qual estava em maior concentração na formulação. A nanoemulsão apresentou o melhor resultado para melhora da acne, com redução da área das lesões e hiperqueratinização. Essa atividade, muito provavelmente, está relacionada com a forma farmacêutica de apresentação, havendo maior deposição da nanoemulsão na região folicular, onde há a formação de comedões.

A utilização de uso de cosméticos pelos homens impactou, em sua grande maioria, positivamente os participantes, mostrando que os homens não têm uma relação negativa com esses produtos, mas sim um desconhecimento e estranhamento de sua utilização. 
11. REFERÊNCIAS BIBLIOGRÁFICAS 
ABE, Shigeru et al. Suppression of tumor necrosis factor-alpha-induced neutrophil adherence responses by essential oils. Mediators of inflammation, v. 12, n. 6, p. 323-328, 2003.

ABIHPEC, Associação Brasileira da Industria de Higiene Pessoal, Perfumaria e Cosméticos. (2015). Acesso em: 13 jul. 2020.

ABRAMOVITS, William; GONZALEZ-SERVA, Aldo. Sebum, cosmetics, and skin care. Dermatologic clinics, v. 18, n. 4, p. 617-620, 2000.

AGAMA-ACEVEDO, Edith; BELLO-PEREZ, Luis A. Starch as an emulsions stability: the case of octenyl succinic anhydride (OSA) starch. Current Opinion in Food Science, v. 13, p. 78-83, 2017.

ALBANESI, C. et al. Keratinocytes in inflammatory skin diseases. Current Drug TargetsInflammation \& Allergy, v. 4, n. 3, p. 329-334, 2005.

ALBRECHT, S. et al. Skin type differences in solar-simulated radiation-induced oxidative stress. British Journal of Dermatology, n. 180(3), p. 597-603, 2019.

ALVES DA SILVA LIMA, S. The Little Male Secret: Analysis about the male self-concept related to the consumption of beauty products. Tese de doutorado. Dublin, National College of Ireland, 2019.

ANGONESE, R. Ambiente, interpretação e estratégia: um estudo na indústria brasileira de cosméticos. 2008, 241 f. Dissertação (Mestrado em Administração). Universidade Positivo, Curitiba, 2008.

ANVISA - Agência Nacional de Vigilância Sanitária. Guia para Avaliação de Segurança de Produtos Cosméticos, v. I, 2004.

ARNDT, S. et al. Radical protection in the visible and infrared by a hyperforin-rich cream-in vivo versus ex vivo methods. Experimental Dermatology, v. 22, n. 5, p. 354-357, 2013.

BAILEY, S. H. et al. The use of non-invasive instruments in characterizing human facial and abdominal skin. Lasers in surgery and medicine, v. 44. n. 2, p. 131-142, 2012.

BERNEBURG, M.; PLETTENBERG, H.; KRUTMANN, J. Photoaging of human skin. Photodermatology, Photoimmunology \& Photomedicine: Review article, v. 16. n. 6, p. 239244, 2000. 
BHATTACHARYA, P. A review on the impacts of microplastic beads used in cosmetics. Acta Biomedica Scientia, v. 3, n. 1, p. 47-52, 2016.

BIAŁOŃ, M. et al. Chemical Composition of Two Different Lavender Essential Oils and Their Effect on Facial Skin Microbiota. Molecules, v. 24. n. 18, p. 3270, 2019.

calixtoBILIA, A.R. et al. Essential oils loaded in nanosystems: a developing strategy for a successful therapeutic approach. Evidence-Based Complementary and Alternative Medicine, 2014.

BINDER, S. et al. Adverse phototoxic effect of essential plant oils on NIH 3 T3 cell line after UV light exposure. Central European journal of public health, v. 24, n. 3, p. 234-240, 2016.

BOGDAN, C. et al. Improvement of skin condition in striae distensae: Development, characterization and clinical efficacy of a cosmetic product containing Punica granatum seed oil and Croton lechleri resin extract. Drug design, development and therapy, v. 11. p. 521, 2017.

BOUKARI, F. et al. Prevention of melasma relapses with sunscreen combining protection against UV and short wavelengths of visible light: a prospective randomized comparative trial. Journal of the American Academy of Dermatology, v. 72. n. 1, p. 189-190, 2015.

BRANZAN, A.L.; LANDTHALER, M.; SZEIMIES, R.M. In vivo confocal scanning laser microscopy in dermatology. Lasers Med Sci, v.22, n.2, p. 73-82, 2007.

BREATHNACH, A. S.; WYLLIE, L. M. Electron microscopy of melanocytes and melanosomes in freckled human epidermis. Journal of Investigative Dermatology, v. 42., n. 5, p. 389-394, 1964.

CALIXTO, L. S.; INFANTE, V. H. P.; CAMPOS, P. M.B.G. M. Design and characterization of topical formulations: correlations between instrumental and sensorial measurements. AAPS PharmSciTech, v. 19, n. 4, p. 1512-1519, 2018.

CALIXTO, L. S.; MAIA CAMPOS, P. M. B. G. Physical-Mechanical characterization of cosmetic formulations and correlation between instrumental measurements and sensorial properties. International journal of cosmetic science, v. 39, n. 5, p. 527-534, 2017.

CALIXTO, L. S., et. al. Interactions between UV filters and active substances in emulsion: effect on microstructure, physicochemical and in-vivo properties. International Journal of Pharmaceutics, v. 553, n.1-2, p. 220-228, 2018. 
CALIXTO, L. S. et al. Brazilian and French sensory perception of complex cosmetic formulations: a cross-cultural study. International Journal of Cosmetic Science, v. 42, n. 1, p. 60-67, 2020.

CANNAS, S. et al. Chemical composition, cytotoxicity, antimicrobial and antifungal activity of several essential oils. Natural product research, v. 30, n. 3, p. 332-339, 2016.

CARDIA, G. F. E. et al. Effect of lavender (Lavandula angustifolia) essential oil on acute inflammatory response. Evidence-Based Complementary and Alternative Medicine, 2018.

CARVALHO, J.D.R. Vaidade masculina: um estudo sobre a mudança de hábitos do homem contemporâneo. 2010. Monografia (Comunicação Social, ênfase em Publicidade e Propaganda). Centro Universitário de Brasília, Brasília, 2010.

CAVANAGH, H. M. A.; WILKINSON, J. M. Lavender essential oil: a review. Australian infection control, v. 10, n. 1, p. 35-37, 2005.

CHOE, C. S.; LADEMANN, J.; DARVIN, M. E. Gaussian-function-based deconvolution method to determine the penetration ability of petrolatum oil into in vivo human skin using confocal Raman microscopy. Laser Physics, v. 24, n. 10, 105601, 2014.

CHOE, C. S.; LADEMANN, J.; DARVIN, M. E. Analysis of human and porcine skin in vivo/ex vivo for penetration of selected oils by confocal Raman microscopy. Skin pharmacology and physiology, v. 28, n. 6, p. 318-330, $2015 \mathrm{a}$.

CHOE, C. S.; LADEMANN, J.; DARVIN, M. E. Confocal Raman microscopy for investigating the penetration of various oils into the human skin in vivo. Journal of Dermatological Science, v. 79, n. 2, p. 176-178, 2015 b.

CHOE, C. S. et al. Keratin-water-NMF interaction as a three-layer model in the human stratum corneum using in vivo confocal Raman microscopy. Scientific reports, v. 7, n. 1, p. 1-13, 2017.

CHULAROJANAMONTRI, L. et al. Moisturizers for acne: what are their constituents? The Journal of clinical and aesthetic dermatology, v. 7, n. 5, p. 36, 2014.

COOK, T. H. et al. Quantification of the skin's topography by skin profilometry. International Journal of Cosmetic Science, v. 4, n. 5, p. 195-205, 1982.

COSTA, A., ALCHORNE, M. M. A., GOLDSCHMIDT, M. C. B. Fatores etiopatogênicos da acne vulgar. Anais brasileiros de dermatologia, 2008. 
COURTENAY, W. H. Constructions of masculinity and their influence on men's well-being. Coll Men Masculinities Theory Res Implic Pract, 307, 2010.

COWLEY, K.; VANOOSTHUYZE, K. Insights into shaving and its impact on skin. British Journal of Dermatology, v. 166, p. 6-12, 2012.

CREIGHTON, G.; OLIFFE, J. L. Theorising masculinities and men's health: A brief history with a view to practice. Health Sociology Review, v. 19, n. 4, p. 409-418, 2010.

CHRISTENSEN, L. et al. Bacterial infection as a likely cause of adverse reactions to polyacrylamide hydrogel fillers in cosmetic surgery. Clinical infectious diseases, v. 56, n. 10, p. 1438-1444, 2013.

CROWTHER, J. M. Method for quantification of oils and sebum levels on skin using the Sebumeter®. International Journal of Cosmetic Science, v. 38, n. 2, p. 210-216, 2016.

DA CUNHA, M. G.; DA CUNHA, A. L. G.; MACHADO, C. A. Hipoderme e tecido adiposo subcutâneo: duas estruturas diferentes. Surgical \& cosmetic dermatology, v. 6, n. 4, p. 355359.

DARLENSKI, R.; FLUHR, J. W. Influence of skin type, race, sex, and anatomic location on epidermal barrier function. Clinics in dermatology, v. 30, n. 3, p. 269-273, 2012.

DA SILVA, J. K. D. et al. O comportamento de compra e consumo de cosméticos: um estudo exploratório. Gestión Joven, v. 19, n. 10, 2019.

DAS, S.; REYNOLDS, Rachel V. Recent advances in acne pathogenesis: implications for therapy. American journal of clinical dermatology, v. 15, n. 6, p. 479-488, 2014.

DE BEAUVOIR, Simone. O segundo sexo. Nova Fronteira, 2014.

DECKER, A., GRABER, E. M. Over-the-counter acne treatments: a review. The Journal of clinical and aesthetic dermatology, v. 5, n. 5, p. 32, 2012.

DEPLEWSKI, D. ROSENFIELD, R. L. Role of hormones in pilosebaceous unit development. Endocrine reviews, v. 21, n. 4, p. 363-392, 2000.

DE MELO, M. O., MAIA CAMPOS, P. M. B. G. Characterization of oily mature skin by biophysical and skin imaging techniques. Skin Research and Technology, v. 24, n. 3, p. 386$395,2018$. 
DE MELO, M. O., MAIA CAMPOS, P. M. B. G. Application of biophysical and skin imaging techniques to evaluate the film-forming effect of cosmetic formulations. International Journal of Cosmetic Science, v. 41, n. 6, p. 579-584, 2019.

DE JESUS, J. G. Orientações sobre identidade de gênero: conceitos e termos. Brasília: Autor, 2012.

DE MORAES KYRILLOS, G.; ALMEIDA, L. F. Mídia: uma ferramenta a favor ou contra a redefinição das características de gênero? Revista Habitus - IFSC/UFRJ, v. 8, n. 2, 2015.

DEYNO, S. et al. Essential oils as topical anti-infective agents: A systematic review and metaanalysis. Complementary therapies in medicine, v. 47, p. 102224, 2019.

DHAKAD, A. K. et al. Biological, medicinal, and toxicological significance of Eucalyptus leaf essential oil: a review. Journal of the Science of Food and Agriculture, v. 98, n. 3, p. 833$848,2018$.

DOBREV, H. Clinical and instrumental study of the efficacy of a new sebum control cream. Journal of cosmetic dermatology, v. 6, n. 2, p. 113-118, 2007.

DÓRIA, L. B. A mudança de representação da masculinidade no discurso publicitário: uma análise da desconstrução de gênero nas marcas Avon e Natura. 2017. 81 f. Trabalho de Conclusão de Curso (Graduação em Comunicação - Habilitação em Publicidade e Propaganda) - Escola de Comunicação, Universidade Federal do Rio de Janeiro, Rio de Janeiro, 2017.

DRÉNO, B. et al. Cutibacterium acnes (Propionibacterium acnes) and acne vulgaris: a brief look at the latest updates. Journal of the European Academy of Dermatology and Venereology, v. 32, p. 5-14, 2018.

DUARTE, C. A. L. et al. Are men really different from women?: analysis of men buying behaviour of cosmetic products. 2019. Tese de doutorado - Universidade Católica Portuguesa, 2019.

DUBUISSON, P. et al. How does composition influence the texture of cosmetic emulsions?. Colloids and Surfaces A: Physicochemical and Engineering Aspects, 2018, 536. Jg., S. 3846.

DUTRA, Mirian Gisele Escobar. Vaidade masculina: a percepção do homem sobre a beleza e os cuidados com a aparência. 2010. 
ELPELT, A. et al. Insight into the redox status of inflammatory skin equivalents as determined by EPR spectroscopy. Chemico-biological interactions, v. 310, s. 108752, 2019.

ENSHAIEH, S. et al. The efficacy of 5\% topical tea tree oil gel in mild to moderate acne vulgaris: a randomized, double-blind placebo-controlled study. Indian Journal of Dermatology, Venereology, and Leprology, v. 73, n. 22, v. 1, 2007.

ESCOBAR-CHAVEZ, J. J. et al. The tape-stripping technique as a method for drug quantification in skin. Journal of pharmacy \& pharmaceutical sciences, v. 11, n. 1, p. 104$130,2008$.

ESSENDOUBI, M., et al. Human skin penetration of hyaluronic acid of different molecular weights as probed by Raman spectroscopy. Skin Research and Technology, v. 22, n. 1, p. 55$62,2016$.

ESTANQUEIRO M, AMARAL MH, SOUSA LOBO JM. Comparison between sensory and instrumental characterization of topical formulations: impact of thickening agents. International Journal of Cosmetic Science, v. 38, n. 4, p. 389-98, 2016.

EUROMONITOR INTERNATIONAL. About Euromonitor International. Disponível em: $<$ https://www.euromonitor.com/pt - euromonitor - about - us $>$. Acessado em: <03.30.2020.>

FARAG, N. F. et al. Characterization of essential oils from Myrtaceae species using ATR-IR vibrational spectroscopy coupled to chemometrics. Industrial Crops and Products, v. 124, p. 870-877, 2018.

FARRAR, M. D., INGHAM, E. Acne: inflammation. Clinics in dermatology, v. 22, n. 5, p. 380-384, 2004.

FAUCHEUX, E. et al. Residual film formation after emulsion application: understanding the role and fate of excipients on skin surface. International Journal of Pharmaceutics, s. 119453, 2020.

FERNANDES, A. B. R. A. O discurso e a construção do homem 2.0: um estudo sobre o papel da comunicação na expansão do mercado masculino de beleza no Brasil a partir do caso Men's Market. 2016. 98 f. Trabalho de Conclusão de Curso (Graduação em Comunicação Habilitação em Publicidade e Propaganda) - Escola de Comunicação, Universidade Federal do Rio de Janeiro, Rio de Janeiro, 2016. 
FERREIRA, V. T. P. et al. Application of Factorial Design and Rheology to the Development of Photoprotective Formulations. Aaps Pharmscitech, v. 21, n. 2, s. 46, 2020.

FICHEUX, A. S. et al. Consumption of cosmetic products by the French population second part: amount data. Food and Chemical Toxicology, v. 90, p. 130-141, 2016.

FICHEUX, A.S. et al. Consumption and exposure to finished cosmetic products: A systematic review. Food and Chemical Toxicology, v. 124, p. 280-299, 2019.

FIROOZ, A. et al. Variation of biophysical parameters of the skin with age, gender, and body region. The Scientific World Journal, 2012.

FLAMENT, F. et al. Effect of the sun on visible clinical signs of aging in Caucasian skin. Clinical, cosmetic and investigational dermatology, v. 6, s. 221, 2013.

FONSECA, P. Co. Ser um homem feminino? Como a publicidade contribui para a desigualdade de gênero. Temática, v. 11, n. 4, 2015.

FORBES. Beleza masculina vai alcançar US\$78,6 bilhões em 2023. Disponível em: https://forbes.com.br/negocios/2020/02/beleza-masculina-vai-alcancar-us-786-bilhoes-em2023/. Acesso em: 06 de agosto de 2020 às 09:50.

FOSSA SHIRATA, M. M.; CAMPOS, PMBG Maia. Influence of UV filters on the texture profile and efficacy of a cosmetic formulation. International Journal of Cosmetic Science, $\mathrm{v}$ 39, n. 6, p. 622-628, 2017.

FOSSA, M. M. S.; MAIA CAMPOS, P. M. B. G. Importance of texture profile and sensory evaluation in the dermocosmetic development. Surgical Cosmetic Dermatolology, n. 8., p. 223$230,2018$.

FRENCH, D. Organization of starch granules. In: Starch: Chemistry and technology. Academic Press, p. 183-247, 1984.

FURTADO, J.A. Título do trabalho: Identidade masculina e publicidade: Uma discussão contemporânea. In: III ENECULT - Encontro de Estudos Multidisciplinares em Cultura, 2007.

GALDAS, P. M.; CHEATER, F.; MARSHALL, P. Men, and health help-seeking behaviour: literature review. Journal of advanced nursing, v. 49, n. 6, p. 616-623, 2005.

GASPAR, L. R.; CAMPOS, P. M. B. G. Rheological behavior, and the SPF of sunscreens. International journal of pharmaceutics, v. 250, n. 1, p. 35-44, 2003. 
GASPAR, L. R. et al. Skin phototoxicity of cosmetic formulations containing photounstable and photostable UV-filters and vitamin A palmitate. Toxicology in vitro, v. 27, n.1, p. 418-425, 2013.

GIANETI, M. D., MERCURIO, D. G., MAIA CAMPOS, P. M. B. G. The use of green tea extract in cosmetic formulations: not only an antioxidant active ingredient. Dermatologic therapy, v. 26, n. 3, p. 267-271, 2013.

GILBERT, L., et al. Impact of polymers on texture properties of cosmetic emulsions: a methodological approach. Journal of sensory studies, v. 27, n. 5, p. 392-402, 2012.

GLAAD. Media Reference Guide 2016. New York e Los Angeles, 2016. Disponível em: <https://www.glaad.org/reference>. Acesso em 02 jun. 2020.

GNIADECKA, M., JEMEC, G. B. E. Quantitative evaluation of chronological ageing and photoageing in vivo: studies on skin echogenicity and thickness. British Journal of Dermatology, v. 139, n. 5, p. 815-821, 1998.

GONZÁLEZ, S.; GILABERTE-CALZADA, Y. In vivo reflectance-mode confocal microscopy in clinical dermatology and cosmetology. International Journal of Cosmetic Sciences, v. 30, n.1, p. 1-17, 2008.

GRIFFITH, D. M., et al. Masculinity in men's health: Barrier or portal to healthcare? In: Men's health in primary care. Humana Press, Cham, 2016. S. 19-31.

GUARATINI, T., GIANETI, M. D., CAMPOS, P. M. B. G. Stability of cosmetic formulations containing esters of Vitamins E and A: chemical and physical aspects. International journal of pharmaceutics, v. 327, n. 1-2, p. 12-16, 2006.

HAAG, S. F. et al. Comparative study of carotenoids, catalase and radical formation in human and animal skin. Skin pharmacology and physiology, v. 23, n. 6, p. 306-312, 2010.

HAMMER, K. A. Treatment of acne with tea tree oil (melaleuca) products: a review of efficacy, tolerability and potential modes of action. International journal of antimicrobial agents, $\mathrm{v}$. 45, n. 2, p. 106-110, 2015.

HARPER, R. A., GROVE, G. Human skin fibroblasts derived from papillary and reticular dermis: differences in growth potential in vitro. Science, v. 204, n. 4392, p. 526-527, 1979. 
HERMAN, A., HERMAN, A. P. Essential oils and their constituents as skin penetration enhancer for transdermal drug delivery: a review. Journal of Pharmacy and Pharmacology, v. 67, n. 4, p. 473-485, 2015.

HUNTER, A.; TREVINO, M. Film formers enhance water resistance and SPF in sun care products. Cosmetics and Toiletries, v.119, n. 7, p. 51-56, 2004.

INFANTE, V. H. P., CALIXTO, L. S.; CAMPOS, P. M. B. G. M. Cosmetics consumption behavior among men and women and the importance in products indication and treatment adherence. Surgical and Cosmetic Dermatology, v. 8, n. 2, 2016.

INFANTE, V. H. P., CALIXTO, L. S.; CAMPOS, P. M. B. G. Propriedades físico mecânicas de formulações tópicas à base de diferentes polímeros. Biomedical and Biopharmaceutical Research, v. 16, n. 2, p. 213-222, 2019.

INFANTE, V. H. P., DE MELO, M. O., MAIA CAMPOS, P. M. B. G. The social and scientifical evolution of the cosmetic science-a brasilein view. Biomedical and Biopharmaceutical Research, v. 15, n. 1, p. 82-93, 2018.

INFANTE, V.H.P., CALIXTO, L.S., MAIA CAMPOS, P.M.B.G. Application of tapioca and corn starches as an alternative for synthetic polymers in cosmetic products. Brazilian Journal of Pharmaceutical Sciences, 2020 (in press).

INFANTE, V.H.P. et al. Influence of physical-mechanical properties on SPF in sunscreen formulations on ex vivo and in vivo skin. International Journal Pharmaceutics, v. 598, $120262,2021 \mathrm{a}$

INFANTE, V.H.P., BAGATIN, E., MAIA CAMPOS, P.M.B.G. Skin photoaging in young men: a clinical study by skin imaging techniques. International Journal of Cosmetic Sciences, $2021 b$.

INFANTE, V.H.P. et al. Eco-friendly sunscreen formulation based on starches and PEG-75 lanolin increases the antioxidant capacity and the light scattering activity in the visible light. Photochemistry and Photobiology B: Biology, 2021c (submetido).

JOSHI, Laxmi S.; PAWAR, Harshal A. Herbal cosmetics and cosmeceuticals: An overview. Nat Prod Chem Res, 2015, 3. Jg., Nr. 2, S. 170.

JUNQUEIRA, L. C., CARNEIRO, J., CASAROLI-MARANO, R. P. Histologia básica. Barcelona: Masson, 2013. 
KAMINSKY, A. et al. Large prospective study on adult acne in Latin America and the Iberian Peninsula: risk factors, demographics, and clinical characteristics. International journal of dermatology, v. 58, n. 11, p. 1277-1282, 2019.

KAZEMI, M. et al. Deep skin wound healing potential of lavender essential oil and licorice extract in a nanoemulsion form: Biochemical, histopathological and gene expression evidence. Journal of Tissue Viability, 2020.

KEJLOVÁ, K., et al. Phototoxicity of bergamot oil assessed by in vitro techniques in combination with human patch tests. Toxicology in Vitro, v. 21, n. 7, p. 1298-1303, 2007.

KEJLOVÁ, K., et al. Phototoxicity of essential oils intended for cosmetic use. Toxicology in vitro, v. 24, n. 8, p. 2084-2089, 2010.

KHAN, I. et al. Men's attitude and motivation toward consumption of grooming products: A comparison of Chinese and Pakistani male consumers. Cogent Business \& Management, v. 4, n. 1, s. 1309783, 2017.

KIM, B. Y., SHIN, S. Antimicrobial and improvement effects of tea tree and lavender oils on acne lesions. Journal of Convergence Information Technology, v. 8, n. 13, p. 339, 2013.

KRUTMANN, J. et al. The skin aging exposome. Journal of dermatological science, v. 85, n. 3, p. 152-161, 2017.

KWANGJAI, J. et al. Modification of brain waves and sleep parameters by Citrus reticulata Blanco. cv. Sai-Nam-Phueng essential oil. Biomedical Journal, 2020.

LADEMANN, J. et al. Synergy effects between organic and inorganic UV filters in sunscreens. Journal of biomedical optics, v. 10, n. 1, s. 014008, 2005.

LADEMANN, J. et al. Hair follicles-a long-term reservoir for drug delivery. Skin pharmacology and physiology, v. 19, n. 4, p. 232-236, 2006.

LADEMANN, J. et al. Hair follicles-an efficient storage and penetration pathway for topically applied substances. Skin pharmacology and physiology, v. 21, n. 3, p. 150-155, 2008.

LASAGNI, C., SEIDENARI, S. Echographic assessment of age-dependent variations of skin thickness: A study on 162 subjects. Skin Research and Technology, v. 1, n. 2, p. 81-85, 1995. 
LEITE, M. G. A., MAIA CAMPOS, P. M. B. G. Correlations between sebaceous glands activity and porphyrins in the oily skin and hair and immediate effects of dermocosmetic formulations. Journal of cosmetic dermatology, v.19, n. 11, p. 3100-3106, 2020.

LEITE, M. G., MAIA CAMPOS, P. M. B. G. Development, and efficacy evaluation of hair care formulations containing vegetable oils and silicone. International Journal of Phytocosmetics and Natural Ingredients, v. 5, n. 1, p. 9-19, 2018.

LEITE, M. G., Maia Campos, P. M. B. G. Development of shampoo formulations with guarana extract: Influence of thickening agents in the texture profile. International Journal of Phytocosmetics and Natural Ingredients, v. 7, n. 1, p. 6-6, 2019.

LERTSATITTHANAKORN, P. et al. In vitro bioactivities of essential oils used for acne control. International Journal of Aromatherapy, v. 16, n. 1, p. 43-49, 2006.

LESLIE, H. A. Review of microplastics in cosmetics. IVM Institute for Environmental Studies, v. 476, p. 1-33, 2014.

LEVEQUE, J. L. et al. In vivo studies of the evolution of physical properties of the human skin with age. International journal of dermatology, v. 23, n. 5, p. 322-329, 1984.

LIN, J. Y., FISHER, D. E. Melanocyte biology and skin pigmentation. Nature, V. 445, N. 7130, p. 843-850, 2007.

LI, X. et al. A review of the role of sebum in the mechanism of acne pathogenesis. Journal of cosmetic dermatology, v. 16, n. 2, p. 168-173, 2017.

LOHAN, S. B. et al. Determination of the antioxidant status of the skin by in vivo-electron paramagnetic resonance (EPR) spectroscopy. Cosmetics, v. 2, n. 3, p. 286-301, 2015.

LÖKEN, L. S., OLAUSSON, H. The skin as a social organ. Experimental brain research, v. 204, n. 3, p. 305-314, 2010.

LONGO, C. et al. Skin aging: in vivo microscopic assessment of epidermal and dermal changes by means of confocal microscopy. Journal of the American Academy of Dermatology, v. 68, n. 3, p. e73-e82, 2013.

LONGO, C. et al. Laser skin rejuvenation: epidermal changes and collagen remodeling evaluated by in vivo confocal microscopy. Lasers in medical science, v. 28, n. 3, p. 769-776, 2013. 
LONGO, C., Pellacani, G. Reflectance confocal microscopy. European Handbook of Dermatological Treatments. Springer, Berlin, Heidelberg, 1129-1137, 2015.

LORETZ, L. J. et al. Exposure data for cosmetic products: lipstick, body lotion, and face cream. Food and Chemical Toxicology, v. 43, n. 2, p. 279-291, 2005.

LUEBBERDING, S., KRUEGER, N., KERSCHER, M. Skin physiology in men and women: in vivo evaluation of 300 people including TEWL, SC hydration, sebum content and skin surface pH. International journal of cosmetic Science, v. 35, n. 5, p. 477-483, 2013.

LUEBBERDING, S., KRUEGER, N., KERSCHER, M. Mechanical properties of human skin in vivo: a comparative evaluation in 300 men and women. Skin Research and Technology, v. 20, n. 2, p. 127-135, 2014a.

LUEBBERDING, S., KRUEGER, N., KERSCHER, M. Quantification of age-related facial wrinkles in men and women using a three-dimensional fringe projection method and validated assessment scales. Dermatologic Surgery, v. 40, n. 1, p. 22-32, 2014 b.

LUTHER, N. et al. Ethnic differences in skin physiology, hair follicle morphology and follicular penetration. Skin pharmacology and physiology, v. 25, n. 4, p. 182-191, 2012.

MACIEL, B. et al. Implementation of an in vitro methodology for phototoxicity evaluation in a human keratinocyte cell line. Toxicology in Vitro, v. 61, s. 104618, 2019.

MAIA CAMPOS, P. M. B. G., MELO, M. O., MERCURIO, D. G. Use of advanced imaging techniques for the characterization of oily skin. Frontiers in Physiology, v. 10, n. 254, 2019.

MAIA CAMPOS, P. M. B. G. et al. Cichorium intybus root extract: A “vitamin D-like” active ingredient to improve skin barrier function. Journal of Dermatological Treatment, v. 28, n. 1, p. 78-81, 2017.

MANDAL, S., MANDAL, M. Coriander (Coriandrum sativum L.) essential oil: Chemistry and biological activity. Asian Pacific Journal of Tropical Biomedicine, v. 5, n. 6, p. 421-428, 2015. MANFREDINI, M. et al. Does skin hydration influence keratinocyte biology? In vivo evaluation of microscopic skin changes induced by moisturizers by means of reflectance confocal microscopy. Skin research and technology, v. 19, n. 3, p. 299-307, 2013.

MANFREDINI, M. et al. Acne: in vivo morphologic study of lesions and surrounding skin by means of reflectance confocal microscopy. Journal of the European Academy of Dermatology and Venereology, v. 29, n. 5, p. 933-939, 2015. 
MANFREDINI, M. et al. In vivo monitoring of topical therapy for acne with reflectance confocal microscopy. Skin Research and Technology, v. 23, n. 1, p. 36-40, 2017.

MAN, M. Q. et al. Variation of skin surface $\mathrm{pH}$, sebum content and stratum corneum hydration with age and gender in a large Chinese population. Skin pharmacology and physiology, v. 22, n. 4, p. 190-199, 2009.

MANN, T. et al. High-energy visible light at ambient doses and intensities induces oxidative stress of skin-Protective effects of the antioxidant and Nrf2 inducer Licochalcone A in vitro and in vivo. Photodermatology, photoimmunology \& photomedicine, v. 36, n. 2, p. 135-144, 2020.

MARTINI, A. P. M., MAIA CAMPOS, P. M. B. G. Influence of visible light on cutaneous hyperchromias: clinical efficacy of broad-spectrum sunscreens. Photodermatology, Photoimmunology \& Photomedicine, v. 34, n. 4, p. 241-248, 2018.

MARTINI, A. P. M., MERCURIO, D. G.; MAIA CAMPOS, P. M. B. G. Assessment of skin pigmentation by confocal microscopy: Influence of solar exposure and protection habits on cutaneous hyperchromias. Journal of Cosmetic Dermatology, v. 16, n. 3, p. 364-369, 2017.

MAXIMO, A. R., Leite, R. S. Sou homem com H! O movimento migratório do consumo de produtos de beleza. Consumer Behavior Review, v. 4, n. 1, p. 19-37, 2020.

MAZZARELlO, Vi. et al. Clinical Assessment of New Topical Cream Containing Two Essential Oils Combined with Tretinoin in the Treatment of Acne. Clinical, Cosmetic and Investigational Dermatology, v. 13, n. 233, 2020.

MCCARTY, M. Evaluation and management of refractory acne vulgaris in adolescent and adult men. Dermatologic clinics, v. 34, n. 2, p. 203-206, 2016.

MCKENZIE, C., RADEMAKER, A. W., KUNDU, R. V. Masculine norms and sunscreen use among adult men in the United States: A cross-sectional study. Journal of the American Academy of Dermatology, v. 81, n. 1, p. 243-244, 2019.

MEINKE, M. C. et al. Radical protection by sunscreens in the infrared spectral range. Photochemistry and photobiology, v. 87, n. 2, p. 452-456, 2011.

MERCURIO, D. G. et al. Clinical scoring and instrumental analysis to evaluate skin types. Clinical and Experimental Dermatology, v. 38, n. 3, p. 302-309, 2013. 
MERCURIO, D. G. et al. Morphological, structural and biophysical properties of French and Brazilian photoaged skin. British Journal of Dermatology, v. 174, n. 3, p. 553-561, 2016.

MIZUKOSHI, K., AKAMATSU, H. The investigation of the skin characteristics of males focusing on gender differences, skin perception, and skin care habits. Skin Research and Technology, v. 9, n. 2, p. 91-99, 2013.

MILLER, J. Making up is masculine: The increasing cultural connections between masculinity and make-up. Critical Studies in Men's Fashion, v. 1, n. 3, p. 241-253, 2014.

MILLER, T. A metrosexual eye on queer guy. GLQ: A Journal of Lesbian and Gay Studies, v. 11, n. 1, p. 112-117, 2005.

MOZDZENSKI, L., AGUIAR, P. D. Entre cabras-machos, ogros e o 'novo homem': o ethos e o pathos construindo masculinidades em propagandas de cosméticos masculinos.

MÜNDLEIN, M. et al. Comparison of transepidermal water loss (TEWL) measurements with two novel sensors based on different sensing principles. Sensors and Actuators A: Physical, v. 142, n. 1, p. 67-72, 2008.

NAKAHARA, T. et al. Analysis of sebum lipid composition and the development of acneiform rash before and after administration of EGFR inhibitor. Current oncology, v. 22, n.2, e. 124, 2015.

NAKAHIGASHI, N., SUGAI, T. Assesment of Degeneration by Sun-Exposure Using Ultrasonic Imaging with Dermascan C. Skin research, v. 38, n. 1, p. 25-30, 1996.

NATHALIE, D. et al. Assessment of the phototoxic hazard of some essential oils using modified 3T3 neutral red uptake assay. Toxicology in vitro, v. 20, n. 4, p. 480-489, 2006.

NATIONAL CANCER INSTITUTE. SEER Surveillance Epidemiology and End Results. 2011-2015. Cancer Stat Facts: Melanoma of the Skin. Disponível em: https://seer.cancer.gov/statfacts/html/melan.html. Acessado em 09 de julho de 2020.

NIKOLIĆ, S., et al. Skin photoprotection improvement: synergistic interaction between lipid nanoparticles and organic UV filters. International journal of pharmaceutics, v. 414, n. 1-2, p. 276-284, 2011.

OBA, A. et al. A non-invasive method for measuring invisible subcutaneous UV damage. In: 22 ${ }^{\text {nd }}$ IFSCC Congress, 2002, Edinburgh. Cosmetic Science for a Global Marketplace, CDROM, 2002. 
OEDC - Organization for Economic Co-operation and Development, OECD Guidelines for Testing of Chemicals Test no. 432: In Vitro 3T3 NRU Phototoxicity Test, 2004. Disponível em: https://ntp.niehs.nih.gov/iccvam/suppdocs/feddocs/oecd/oecdtg432-508.pdf (Acessado em 04 de fevereiro de 2019

OLIVEIRA, P. F. et al. Cytotoxicity screening of essential oils in cancer cell lines. Revista Brasileira de Farmacognosia, v. 25, n. 2, p. 183-188, 2015.

ORCHARD, A. et al. The in vitro antimicrobial evaluation of commercial essential oils and their combinations against acne. International journal of cosmetic science, n. 40, v. 3, p. 226$243,2018$.

OTBERG, N. et al. Variations of hair follicle size and distribution in different body sites. Journal of Investigative Dermatology, v. 122, n. 1, p. 14-19, 2004.

PARK, B. et al. Eucalyptus globulus extract protects against UVB-induced photoaging by enhancing collagen synthesis via regulation of TGF- $\beta /$ Smad signals and attenuation of AP- 1 . Archives of biochemistry and biophysics, n. 637, p. 31-39, 2018.

PARK, G.H. et al. Socioeconomic factors influencing cosmetic usage patterns. Journal of exposure science \& environmental epidemiology, v. 28, n. 3, p. 242-250, 2018.

PASAPANE, J., SOLAREK, D. Specialty Starches for Personal Care [J]. Detergent \& Cosmetics, v. 4, 2001.

PAZYAR, N. et al. A review of applications of tea tree oil in dermatology. International journal of dermatology, v. 52, n. 7, p. 784-790, 2013.

PEI, H. et al. Separation and purification of lanosterol, dihydrolanosterol, and cholesterol from lanolin by high-performance counter-current chromatography dual-mode elution method. Journal of separation science, v. 42, n. 12, p. 2171-2178, 2019.

PELLACANI, G., SEIDENARI, S. Variations in facial skin thickness and echogenicity with site and age. 1999.

POCHI, P. E. et al. Plasma testosterone and estrogen levels, urine testosterone excretion, and sebum production in males with acne vulgaris. The Journal of Clinical Endocrinology \& Metabolism, v. 25, n. 12, p. 1660-1664, 1965. 
POLAŃSKA, A. et al. Comparison between high-frequency ultrasonography (Dermascan C, version 3) and histopathology in atopic dermatitis. Skin Research and Technology, v. 19, n. 4, p. 432-437, 2013.

POMPPER, D. Masculinities, the metrosexual, and media images: Across dimensions of age and ethnicity. Sex roles, v. 63, n. 9-10, p. 682-696, 2010.

PRESS, J., SIMMS, C. Segmenting cosmetic procedures markets using benefit segmentation: A study of the market for tooth whitening services in the United Kingdom. Journal of Medical Marketing, v. 10, n. 3, p. 183-198, 2010.

RAHROVAN, S. et al. Male versus female skin: What dermatologists and cosmeticians should know. International journal of women's dermatology, v. 4, n. 3, p. 122-130, 2018.

REYNOLDS, N. L., SIMINTIRAS, A. C., DIAMANTOPOULOS, A. Theoretical justification of sampling choices in international marketing research: Key issues and guidelines for researchers. Journal of international business studies, v. 34, n. 1, p. 80-89, 2003.

RHODE, A. K. The 'flower men' phenomenon: exploring the cultural encoding of masculinity in south Korean cosmetics advertising. ACR NORTH AMERICAN ADVANCES, 2016.

RIBEIRO, D. L., SILVA, M. L. Cabra macho perfumado: análise do vt publicitário o chamado da marca de cosméticos old spice. Anais do Salão Internacional de Ensino, Pesquisa e Extensão, v. 8, n. 2, 2017.

SAND, J. et al. Expression of inflammasome proteins and inflammasome activation occurs in human, but not in murine keratinocytes. Cell death \& disease, v. 9, n. 2, p. 1-14, 2018.

SARKIC, A., STAPPEN, I. Essential oils and their single compounds in cosmetics-A critical review. Cosmetics, v. 5, n. 1, p. 11, 2018.

SAUERMANN, K. et al. Age-related changes of human skin investigated with histometric measurements by confocal laser scanning microscopy in vivo. Skin Research and Technology, v.8, p. 52-56, 2002.

SAUERMANN, K. et al. Topically applied vitamin C increases the density of dermal papillae in aged human skin. BMC dermatology, v. 4, n. 1, s. 13, 2004.

SCHAEFER, H., LADEMANN, J. The role of follicular penetration. Skin Pharmacology and Physiology, v. 14, n. 1, p. 23-27, 2001. 
SCHEINFELD, N. S. Acne: a review of diagnosis and treatment. P AND T, v. 32, v. 6, s. 340, 2007.

SILVA, L. N. et al. Influence of botanical extracts in the texture profile of shampoo formulations. International Journal of Phytocosmetics and Natural Ingredients, v. 7, n. 1, p. 7-7, 2019.

SISTO, T., BUSSOLETTI, C., CELlENO, L. Efficacy of a cosmetic caffeine shampoo in androgenetic alopecia management. II Note. Journal of Applied Cosmetology, v. 31, n. 1, p. 57-66, 2013.

SHENG, Z. H. O. U. Rapidly development of men' s personal care product market. Detergent \& Cosmetics, v. 4, 2008.

SHI, Y. C., SEIB, P. A. The structure of four waxy starches related to gelatinization and retrogradation. Carbohydrate research, v. 227, p. 131-145, 1992.

SHUGART, H. Managing masculinities: The metrosexual moment. Communication and Critical/Cultural Studies, v. 5, n. 3, p. 280-300, 2008.

SKROZA, N. et al. Adult acne versus adolescent acne: a retrospective study of 1,167 patients. The Journal of clinical and aesthetic dermatology, v. 11, n. 1, s. 21, 2018.

SMITH, C. et al. A novel combined experimental-numerical approach for determination of mechanical proprieties of skin in vivo. In: 22 ${ }^{\text {nd }}$ IFSCC Congress, 2002, Edinburgh. Cosmetic Science for a Global Marketplace, CD-ROM, 2002.

SMITHERS, D. W., WOOD, J. H. Xeroderma pigmentosum an attempt at cancer prophylaxis. The Lancet, v. 259, n. 6715, p. 945-946, 1952.

SOLOMON, M. R. O Comportamento do consumidor-: comprando, possuindo e sendo. Bookman Editora, 2016.

SOUIDEN, N., DIAGNE, M. Canadian and French men's consumption of cosmetics: a comparison of their attitudes and motivations. Journal of Consumer marketing, 2009.

SOUTHWELL, I. A., FREEMAN, S., RUBEL, D. Skin irritancy of tea tree oil. Journal of Essential Oil Research, v. 9, n. 1, p. 47-52, 1997.

SOUZA, R. C. R., ANDRADE, C. T. Investigação dos processos de gelatinização e extrusão de amido de milho. Polímeros, v. 10, n. 1, p. 24-30, 2000. 
SOUZA, A. S. Discurso e identidade feminina na mídia impressa : a evolução da mulher no mercado de trabalho. Trabalho de conclusão de curso (Graduação em Letras) - Universidade Estadual Paulista "Júlio de Mesquita Filho", Faculdade de Ciências e Letras (Campus de Araraquara) - 2015 ,36 f. ; $30 \mathrm{~cm}$.

SOUZA, C., CAMPOS, P. M. M. Development and photoprotective effect of a sunscreen containing the antioxidants Spirulina and dimethylmethoxy chromanol on sun-induced skin damage. European Journal of Pharmaceutical Sciences, v. 104, p. 52-64, 2017.

SOUZA, C. et al. Radical-scavenging activity of a sunscreen enriched by antioxidants providing protection in the whole solar spectral range. Skin pharmacology and physiology, v. 30, n. 2, p. 81-89, 2017.

STAFA, K. et al. Skin cells can sense and integrate signals coming from eucalyptus extract to combat environmental insults and regenerate from within. In: Journal of Investigative Dermatology. S111-S111, 2019.

STICHER, O., HEILMANN, J., ZÜNDORF, I. Pharmakognosie phytopharmazie. Wissenschaftliche Verlagsgesellschaft Stuttgart, 2015.

SUGATA, K. et al. Confocal laser microscopic imaging of conspicuous facial pores in vivo: relation between the appearance and the internal structure of skin. Skin Research and Technology, v. 14, n. 2, p. 208-2012, 2008.

SWAMY, M. K., SINNIAH, U. R. A Comprehensive review on the phytochemical constituents and pharmacological activities of Pogostemon cablin Benth.: An Aromatic Medicinal Plant of Industrial Importance. Molecules, v. 20, n. 5, p. 8521-8547, 2015.

TAFURO, G. et al. Evaluating Natural Alternatives to Synthetic Acrylic Polymers: Rheological and Texture Analyses of Polymeric Water Dispersions. ACS omega, 2020.

TAI, A., BIANCHINI, R., JACHOWICZ, J. Texture analysis of cosmetic/pharmaceutical raw materials and formulations. International journal of cosmetic science, v. 36, n. 4, p. 291-304, 2016.

TALEB, M. H. et al. Origanum vulgare L. essential oil as a potential anti-acne topical nanoemulsion -in vitro and in vivo study. Molecules, v. 23, n. 9, p. 2164, 2018. 
TAN, J. M. et al. Histopathology and reflectance confocal microscopy features of photodamaged skin and actinic keratosis. Journal of the European Academy of Dermatology and Venereology, v. 30, n. 11, p. 1901-1911, 2016.

TAVARES, R. S. N. et al. Skin irritation testing beyond tissue viability: fucoxanthin effects on inflammation, homeostasis, and metabolism. Pharmaceutics, v. 12, n. 2, p. 136, 2020.

TRIBST, L. T., SOUZA, M. P. P. F. A mudança no conceito da vaidade masculina: uma revisão bibliográfica. Research, Society and Development, v. 9, n.2 , p. e107922127-e107922127, 2020.

ULRICH, C. et al. Prevention of non-melanoma skin cancer in organ transplant patients by regular use of a sunscreen: 24 months, prospective, case-control study. British Journal of Dermatology, v. 161, p. 78-84, 2009.

VALLERAND, I. A. et al. Efficacy and adverse events of oral isotretinoin for acne: a systematic review. British Journal of Dermatology, v. 178, n. 1, p. 76-85, 2018.

VERDUGO, G. B., PONCE, H. R. Gender Differences in Millennial Consumers of Latin America Associated with Conspicuous Consumption of New Luxury Goods. Global Business Review, S. 0972150920909002, 2020.

VIEIRA, G. S. et al. Combining sensory and texturometer parameters to characterize different type of cosmetic ingredients. International Journal of Cosmetic Science, v. 42, n. 2, p. 156$166,2020$.

VINARDELL, M. P., MITJANS, M. Alternative methods to animal testing for the safety evaluation of cosmetic ingredients: an overview. Cosmetics, v. 4, n. 3, p. 30, 2017.

WALSH, T. R., EFTHIMIOU, J., DRÉNO, B. Systematic review of antibiotic resistance in acne: an increasing topical and oral threat. The Lancet Infectious Diseases, v. 16, n. 3, p. e23e33, 2016

WATSON, R. E. B., et al. A cosmetic ‘anti-ageing'product improves photoaged skin: a doubleblind, randomized controlled trial. British Journal of Dermatology, v. 161, n. 2, p. 419-426, 2009.

WEIGMANN, H.J., et al. Determination of penetration profiles of topically applied substances by means of tape stripping and optical spectroscopy: UV filter substance in sunscreens. Journal of biomedical optics, v. 10, n. 1, s. 014009, 2005. 
WERNER, Y. L. V. A. The water content of the stratum corneum in patients with atopic dermatitis. Measurement with the Corneometer CM 420. Acta dermato-venereologica, v. 66, n. 4, s. 281, 1986.

WILHELM, K. P., CUA, A. B.; MAIBACH, H. I. Skin aging: effect on transepidermal water loss, stratum corneum hydration, skin surface $\mathrm{pH}$, and casual sebum content. Archives of dermatology, v. 127, n. 12, p. 1806-1809, 1991.

WILLIAMS, A. C., et al. Molecular interactions between the penetration enhancer 1, 8-cineole and human skin. Journal of Raman Spectroscopy: An International Journal for Original Work in all Aspects of Raman Spectroscopy, Including Higher Order Processes, and also Brillouin and Rayleigh Scattering, v. 37, n. 1-3, p. 361-366., 2006

WLASCHEK, M. et al. Solar UV irradiation and dermal photoaging. Journal of Photochemistry and Photobiology B: Biology, v. 63, n.1-3, p. 41-51, 2001.

WURM, E. M. T. et al. In vivo assessment of chronological ageing and photoageing in forearm skin using reflectance confocal microscopy. British Journal of Dermatology, v. 167, n. 2, p. 270-279, 2012.

ZASTROW, L. et al. From UV protection to protection in the whole spectral range of the solar radiation: new aspects of sunscreen development. In: Ultraviolet Light in Human Health, Diseases and Environment. Springer, Cham, p. 311-318, 2017.

ZEEUWEN, P. L. J. M. et al. Microbiome and skin diseases. Current opinion in allergy and clinical immunology, v. 13, n. 5, p. 514-520, 2013.

ZHU, D. C. et al. Large-Scale Beard Extraction Enhances the Cosmetic Results of Scalp Hair Restoration in Advanced Androgenetic Alopecia in East Asian Men: A Retrospective Study. Dermatology and Therapy, v. 10, n. 1, p. 151-161, 2020.

ZLOTOGORSKI, A. Distribution of skin surface $\mathrm{pH}$ on the forehead and cheek of adults. Archives of dermatological research, v. 279, n. 6, p. 398-401, 1987.

ZOUBOULIS, C. C. Acne and sebaceous gland function. Clinics in dermatology, v. 22, n. 5, p. 360-366, 2004.

ZOUBOULIS, C. C. Acne vulgaris. Der Hautarzt, v. 65, n. 8, p. 733, 2014. 
ZOUBOUlIS, C. C., JOURDAN, E., PICARDO, M. Acne is an inflammatory disease and alterations of sebum composition initiate acne lesions. Journal of the European Academy of Dermatology and Venereology, v. 28, n. 5, p. 527-532, 2014. 